\title{
A Bird's Eye View of Atropisomers Featuring a Five-Membered Ring
}

\author{
Damien Bonne ${ }^{*[a]}$ and Jean Rodriguez ${ }^{*[a]}$
}

Abstract: An atropisomer is a member of a subclass of restricted rotational conformers - this restricted rotation giving rise to stereogenic sigma bonds - that can be isolated as separate chemical species. Most atropisomer are six-membered-ring biaryl or heterobiaryl derivatives. The aim of this microreview is to shed light on a less common class of atropisomers, those containing at least one five-membered hetero- or carbocycle and displaying variously a stereogenic $C-N, C-C$, or even $N-N$ chemical bond. After a short introduction, the occurrence of atropisomers in nature is presented, as well as the synthetic efforts - encompassing non-stereoselective and diastereoselective strategies, together with an update on very recent enantioselective approaches - devoted to such axially chiral compounds. Finally, a special focus is placed on their important utilization as original and efficient ligands for metal complexes.

\section{Introduction}

Nonracemic axially chiral systems of type $\mathbf{1}^{[1]}$ (Scheme 1) are recognized as central elements in many scientific domains, with notably numerous applications in catalyst design, ${ }^{[2]}$ drug discovery, ${ }_{1}^{[3]}$ and materials sciences, ${ }^{[4]}$ and are also widely represented in nature. Among them, six-membered carbocyclic and, to lesser extent, heterocyclic - atropisomers ${ }^{[5]}$ have commanded huge attention over the years and still constitute a central topic of research worldwide, resulting in the development of many elegant synthetic approaches. ${ }^{[6]}$ In sharp contrast, atropisomeric species featuring one or even two fivemembered rings connected variously through a $C-C, C-N$, or

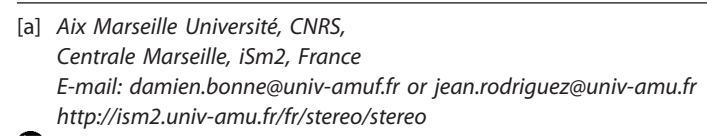

$N-N$ bond have received less attention. ${ }^{[6 i]}$ This situation is basically due to the increased distance between the ortho-substituents $\left(R^{1}\right.$ to $\left.R^{4}\right)$ next to the axis, which is responsible for lower barriers to rotation, hampering the conformational stability (Scheme 1).

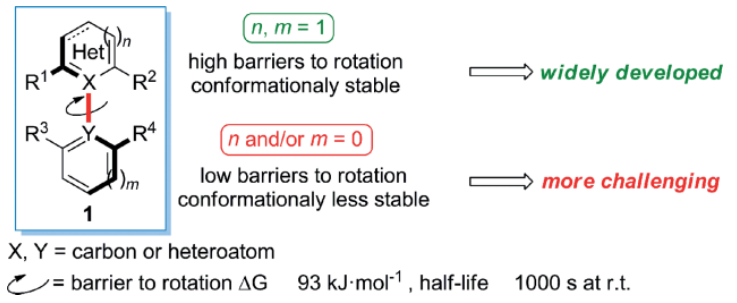

Scheme 1. Situation of six- versus five-membered atropisomeric systems.

Pioneering observations and experimental determinations of barriers to rotation highlight the crucial effect of ortho-substituents. It has been proposed by Oki that a pair of atropisomers

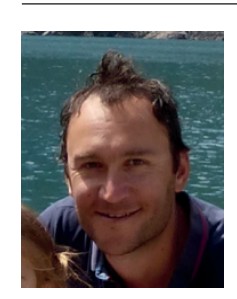

Damien Bonne was born in Epinal (France) in 1979. After studying chemistry at the Ecole Supérieure de Chimie de Lyon (CPE Lyon, France), he completed his Ph.D. in 2006 under the supervision of Prof. J. Zhu, working on isocyanide-based multicomponent reactions. He then moved to the University of Bristol (UK) to join the group of Prof. V. A. Aggarwal as a postdoctoral associate. Since 2007 he has been working as a "Maître de Conférences" (associate professor) at Aix-Marseille University (France). He passed his habilitation (HDR) in 2015 and his research interests include the development of new organocatalyzed methodologies and their application in stereoselective synthesis.

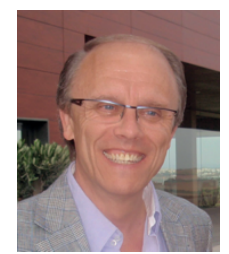

Jean Rodriguez was born in Cieza (Spain) in 1958, and in 1959 his family emigrated to France. After studying chemistry at the University of Aix-Marseille (France), he completed his Ph.D. as a CNRS researcher with Prof. B. Waegell and Prof. P. Brun in 1987. He completed his Habilitation in 1992, also at Marseille, where he is currently Professor and Director of the UMR-CNRS-7313-iSm2. His research interests include the development of multiple bond-forming transformations including domino and multicomponent reactions, and their application in stereoselective organocatalyzed synthesis. In 1998 he was awarded the ACROS prize in Organic Chemistry, in 2009 he was awarded the prize of the Division of Organic Chemistry from the French Chemical Society, and in 2013 he became a "Distinguished Member" of the French Chemical Society. 
should exhibit a minimum energy barrier of $93 \mathrm{~kJ} \mathrm{~mol}^{-1}$, to ensure a half-life of at least 1000 seconds at room temperature ${ }^{[7]}$ and to offer reasonable expectation of the convenient separation of the two enantiomeric atropisomers. ${ }^{[8]}$

In this context, the aim of this microreview, after a brief historical background highlighting their natural occurrence, is to give an overview on the preparation of atropisomers from neglected pioneering achievements up to more contemporaneous selective approaches, including an update on very recent enantioselective syntheses. The last section is devoted to their utilization as efficient ligands for metal complexes, followed by their efficient utilization as ligands for metal complexes.

\section{In Nature}

Both axially chiral $\mathrm{C}-\mathrm{C}$ - and $\mathrm{C}-\mathrm{N}$-bonded atropisomers containing five-membered rings exist in nature, essentially in three small, rare families featuring one or two five-membered rings from the indole, carbazole, or pyrrole series. However, their isolation and characterization were achieved only at the end of the last century (Scheme 2).

a)<smiles>[R]c1[nH]c2ccc(Br)cc2c1-c1c(Br)cc(OC)c2[nH]cc([R])c12</smiles>

2a: $R^{1}=H ; R^{2}=B r$

$2 b: R^{1}=B r ; R^{2}=B r$

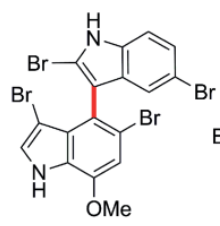

2c

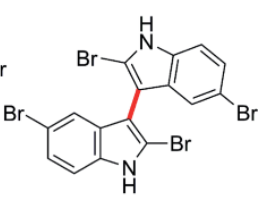

2d<smiles>COc1cc(Br)c(-n2cc(Br)c3cc(Br)ccc32)c2c(Br)c[nH]c12</smiles>

ole atropisomers<smiles></smiles>

$\mathrm{C}-\mathrm{N}$-bonded biindole atropisomers b)
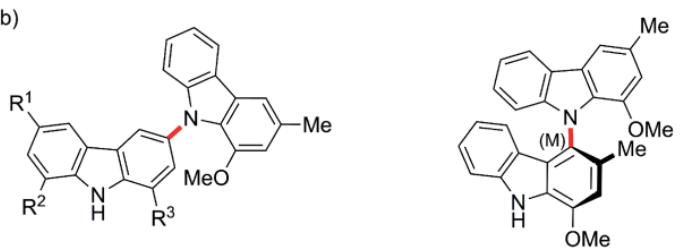

3a: murrastifoline $A\left(R^{1}, R^{2}=M e, O M e, R^{3}=H\right)$

3b : murrastifoline $B\left(R^{1}=R^{2}=H, R^{3}=O M e\right) \quad 3 c:(M)-(+)$-murrastifoline $F$

c)

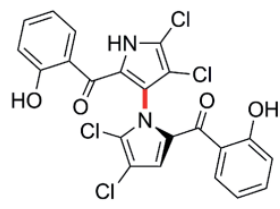

4a : (-)-marinopyrrole A

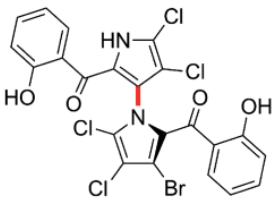

4b : (-)-marinopyrrole B
The first of these families is that of the optically pure polybrominated biindoles $\mathbf{2}$ from marine blue-green alga Rivularia firma, isolated in 1982 and including the four C-C-bonded congeners $\mathbf{2 a}-\mathbf{d}$ and the two $\mathrm{C}-\mathrm{N}$-bonded congeners $\mathbf{2 e}$ and $\mathbf{2 f}$ (Scheme 2a). ${ }^{[9]}$

Another $\mathrm{C}-\mathrm{N}$-bonded carbazole alkaloid family, named murrastifolines A (3a), B (3b), and F (3c), was isolated eleven years later from the acetone extract of the root of the plant Murraya koenigii (Scheme 2b). ${ }^{[10]}$ From the substitution pattern of the axially chiral $C-N$-bonded phenyl ring of murrastifolines $A$ and $\mathrm{B}$, lacking any ortho-substituent, rapid rotation at the biaryl axis was suspected, whereas murrastifoline $F$, bearing four ortho-substituents next to the axis, was expected to be configurationally stable. This was established by Bringmann and collaborators in 2001, both through a very high calculated (AM1) atropisomerization barrier of $165 \mathrm{~kJ} \mathrm{~mol}^{-1}$ and by the unique total synthesis of the $F$ analogue, showing its presence in the root extract as a 56:44 mixture in favor of the $M$ enantiomer. ${ }^{[11]}$

More recently, the two new axially chiral metabolites (-)-marinopyrrole A (4a) and (-)-marinopyrrole B (4b) were isolated after cultivation of an obligate marine Streptomyces strain $^{[12]}$ and showed potent antibiotic activities against methicillin-resistant staphylococcus aureus (Scheme 2c). ${ }^{[13]}$ Two years after their isolation, two different total syntheses of $( \pm)$-marinopyrrole A were reported contemporaneously by the groups of $\mathrm{Li}^{[12 \mathrm{c}]}$ and Sarli, ${ }^{[12 \mathrm{~d}]}$ with nine steps and $30 \%$ yield and six steps and $22 \%$ yield, respectively.

\section{Non-Stereoselective Syntheses}

The first synthesis of an axially chiral five-membered-ring compound was that of $\mathrm{C}-\mathrm{N}$-bonded ${ }^{[14]}$ arylpyrrole $\mathbf{5 a}$, reported back in 1931 by the group of Adams, ${ }^{[15]}$ followed by a series of papers dealing with the preparation of the related arylcarbazole $^{[16]} \mathbf{5 b}$ and the dipyrryl biphenyl $\mathbf{6}^{[17]}$ (Scheme 3). In all these studies, the racemic atropisomers obtained from the required 1,5-diketones and anilines in a Paal-Knorr heterocyclization in the case of $\mathbf{5 a}$ and $\mathbf{6}$ or through the Ullman-type coupling of $o$-iodobenzoic acid with 3-nitrocarbazole in that of $\mathbf{5 b}$ were resolved by means of the corresponding brucine salts. Interestingly, for pyrrole $\mathbf{5} \mathbf{a}$ and carbazole $\mathbf{5} \mathbf{b}$ the two enantiomers were found to be relatively stable in boiling ethanol but to undergo total thermal racemization in the presence of $\mathrm{NaOH}$.

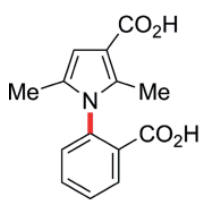

$5 a$

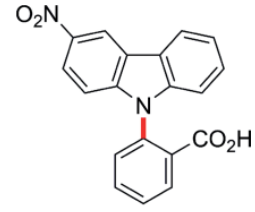

$5 b$<smiles>CCOC(=O)c1cc(C)n(-c2ccc(-c3ccc(-n4c(C)cc(C(=O)OCC)c4C)c(C)c3)cc2C)c1C</smiles>

Scheme 3. First families of axially chiral $\mathrm{N}$-arylpyrroles $\mathbf{5}$ and $\mathbf{6}$. 
After these pioneering contributions, the experimental determination of steric barriers in atropisomers containing five-membered rings became a central research domain of early conformational analysis. This was facilitated by the concomitant development of chiral liquid chromatography, allowing efficient separations of atropisomers as thoroughly studied by Roussel and collaborators, starting in $1985 .^{[18 \mathrm{a}-18 \mathrm{~d}]}$ This strategy was applied to $\mathrm{N}$-arylthiazolinethione derivatives and their oxygen analogues, and later on by Pirkle's, Mannschreck's, and Doğan's groups, notably with related $\mathrm{N}$-aryloxazolinones ${ }^{[18 \mathrm{e}-18 \mathrm{~g}]}$ and $\mathrm{N}$ arylthioxo-oxazolidinones or $\mathrm{N}$-arylrhodanines. ${ }^{[18 \mathrm{~h}, 18 \mathrm{i}]}$ These comparative studies of large series of compounds clearly showed the crucial effect of ortho-substitution on the value of the barriers to rotation, which fluctuated from $38.9 \mathrm{~kJ} \mathrm{~mol}^{-1}$ for ortho-unsubstituted derivatives up to $\geq 134 \mathrm{~kJ} \mathrm{~mol}^{-1}$ (Scheme 4). Interestingly, some specifically functionalized $N$ arylthiazolinethione nuclei have been used either as enantioselective anion receptors for amino acid derivatives ${ }^{[18 j]}$ or as new atropisomeric chiral probes to study supramolecular organization in porphyrin self-assemblies. ${ }^{[18 \mathrm{k}]}$

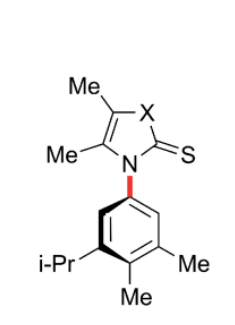

$\mathrm{X}=\mathrm{O}, \mathrm{S}, \mathrm{NMe}$

$\Delta G=38.9-74.0 \mathrm{~kJ} \cdot \mathrm{mol}^{-1}$

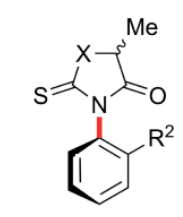

$\mathrm{X}=\mathrm{O}, \mathrm{S}$

$\mathrm{R}=\mathrm{Me}, \mathrm{Cl}$ $\Delta G=104-121 \mathrm{~kJ} \cdot \mathrm{mol}^{-1}$

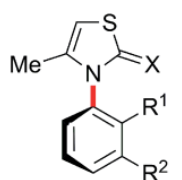

$\mathrm{X}=\mathrm{O}, \mathrm{S}$

$\mathrm{R}^{1}=\mathrm{Me}, \mathrm{Cl}$

$\mathrm{R}^{2}=\mathrm{H}, \mathrm{Me}, \mathrm{Cl}$

$\Delta G=126.9-134 \mathrm{~kJ} \cdot \mathrm{mol}^{-1}$

Scheme 4. Variations of the barriers to rotation in $\mathrm{N}$-arylthiazoline derivatives.

More recently, the groups of Doğan and Roussel independently reported complete experimental and theoretical studies relating to the synthesis of, and the evaluation of the barriers to rotation in, a series of original atropisomeric iminothiazolidinones and iminothiazolines, respectively (Scheme 5). ${ }^{[19 a-19 c]}$ In all of these studies the resolution of atropisomeric enantiomers was achieved by chromatography on chiral supports. In the case of $\mathrm{N}$-aryliminothiazolines, it was found that the barriers significantly decrease when $\mathrm{X}=\mathrm{OH}$ through the creation of an internal hydrogen bond with the nitrogen atom of the imino group, as was corroborated by DFT calculations. The authors

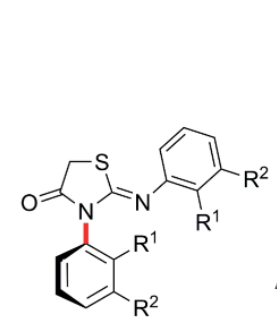

$\mathrm{R}^{1}, \mathrm{R}^{2}=\mathrm{H}, \mathrm{Ph}, \mathrm{Me}, \mathrm{OMe}$

$\Delta G=98.1-114.1 \mathrm{~kJ} \cdot \mathrm{mol}^{-1}$

Scheme 5. Variations of the barriers to rotation in $\mathrm{N}$-aryliminothiazolidinone and -iminothiazoline derivatives. also demonstrated the possibility of forming a rather stable 12-membered-ring diether atropisomer with a slightly higher barrier to rotation.

This unusual intramolecular hydrogen bond effect was exploited four years later by Shimizu's group for the design of original simple molecular rotors featuring compound 7, a $\mathrm{N}-8$ quinolinylsuccinimide framework (Scheme 6). ${ }^{[19 d, 19 e]}$ The authors clearly established that protonation of the quinoline resulted in a dramatic lowering of the barrier to rotation, due to the stabilization of a planar transition state through the formation of an intramolecular hydrogen bond between the protonated nitrogen atom and the imide carbonyl group. Interestingly, the acceleration of the rotation is reversible and can be stopped by addition of base. The determining presence of the nitrogen atom in this specific 8-position was unambiguously established, with no effect being observed with the corresponding control rotors from both the 6-substituted quinoline and the naphthalene series. The same group, upon guest complexation of an acetate ion, observed a closely related effect on the barrier to rotation with $\mathrm{N}$-arylsuccinimides containing a urea recognition group. ${ }^{[19 e]}$

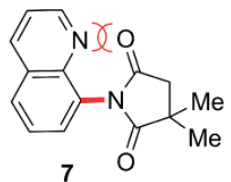

steric repulsion $=$ restricted rotation $\Delta G=92.8 \mathrm{~kJ} \cdot \mathrm{mol}^{-1}$

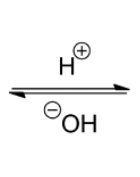

$$
\text { H- }
$$

Scheme 6. Acid-accelerated $\mathrm{N}$-8-quinolinylsuccinimide molecular rotor.

Mintas and collaborators also reported detailed pioneering studies dealing with the synthesis and chromatographic separation of compounds 8, a series of $\mathrm{N}$-aryl- and $\mathrm{N}$-heteroaryl-2,5dimethylpyrrole-3-carbaldehydes variously containing simple phenyl, quinolinyl, thiazolyl, pyridyl, and 6-purinyl groups, and the determination of their barriers to racemization, either experimentally or by calculation (Scheme 7a). ${ }^{[20]}$ Here also, the crucial effect of steric factors next to the axis in reaching the required minimum of $100 \mathrm{~kJ} \mathrm{~mol}^{-1}$ for the barrier to rotation was clearly highlighted. Accordingly, in this series only $\mathrm{N}$ phenyl- and $\mathrm{N}$-quinolinylpyrroles gave room-temperaturestable atropisomers with high calculated free enthalpies of activation: $\Delta G^{\ddagger}=128$ and $130 \mathrm{~kJ} \mathrm{~mol}^{-1}$, respectively. Related enantiopure axially chiral $\mathrm{N}$-phenylpyrrolidones 9 and $\mathrm{N}$-phenyltriazolones $\mathbf{1 0}$ were also obtained by resolution of the corresponding menthol and naproxen esters, respectively (Scheme 7b). ${ }^{[21]}$

More recently, Sugane and co-workers proposed an efficient means of resolution using $(1 R, 2 S)-(-)-2$-amino-1,2-diphenylethanol for the synthesis of the stable atropisomeric $N$-phenyl1,2,4-triazole $(a R)-(-)-\mathbf{1 1}$, which displayed a barrier to rotation of $127 \mathrm{~kJ} \mathrm{~mol}^{-1}$ and exhibited interesting GlyT1-inhibiting properties (Scheme 8). ${ }^{[21 c]}$

In 2016, Ciogli, Mazzanti, and Perumal exploited a new domino reaction between aryl isocyanates $\mathbf{1 2}$ and commercially available 1,4-dithiane-2,5-diol for the synthesis of axially chiral $\mathrm{N}$-arylthiazolinethione derivatives $\mathbf{1 4}$ (Scheme 9). ${ }^{[22]}$ A complete 
a)

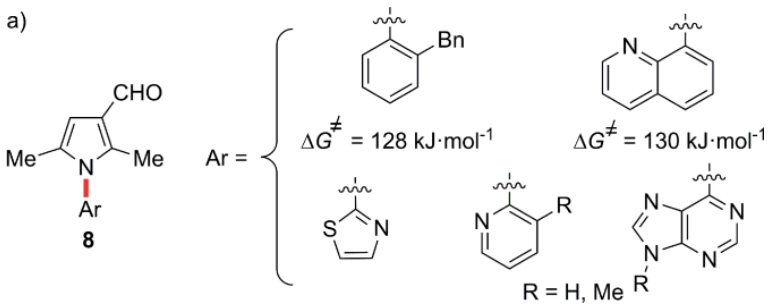

b)

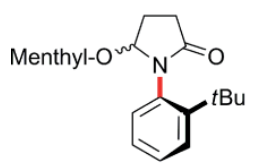

9

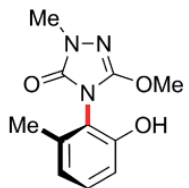

(aS)-(+)-10

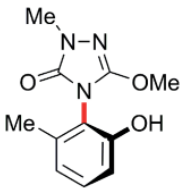

$(a R)-(-)-10$
Scheme 7. $\mathrm{N}$-Aryl and $\mathrm{N}$-heteroaryl axially chiral atropisomers 8-10.<smiles>CCc1nnc(-c2ccc(-c3ccccc3)nc2)n1-c1cccc(C(=O)O)c1C</smiles>

racemic

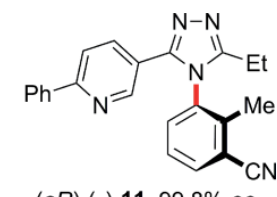

(aR)-(-)-11, 99.8\% ee $\Delta G=127 \mathrm{~kJ} \cdot \mathrm{mol}^{-1}$
Scheme 8. Biologically active $\mathrm{N}$-phenyltriazole $\mathbf{1 1}$.

combined dynamic NMR and HPLC study both of the transient hemiaminal intermediates $\mathbf{1 3}$ and of the $\mathrm{N}$-arylthiazolinethiones 14 allowed the determination of a low barrier to rotation of $90.5 \mathrm{~kJ} \mathrm{~mol}^{-1}$ for $\mathrm{R}=\mathrm{H}$, in agreement with fast atropisomerization at room temperature. In sharp contrast, for $\mathrm{R}=$ Me the barrier to rotation was estimated to be higher than $150.5 \mathrm{~kJ} \mathrm{~mol}^{-1}$, allowing the separation of the two stable enantiomers by chiral HPLC.<smiles>[R]c1ccc2ccccc2c1N=C=S</smiles>

12, $\mathrm{R}=\mathrm{H}$ or $\mathrm{Me}$

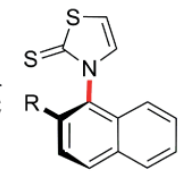

14 $\Delta \mathrm{G}=90.3-150.5 \mathrm{~kJ} \cdot \mathrm{mol}^{-1}$

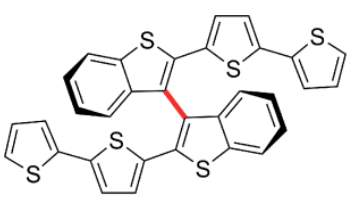

$(a R)-(-)-15$
$\Delta \mathrm{G}=167 \mathrm{~kJ} \cdot \mathrm{mol}^{-1}$

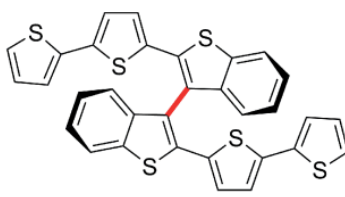

$(a S)-(+)-15$

Scheme 10. C3-C3'-bonded chiral atropisomeric bithienyl derivatives (+)- and $(-)-15$.

Other recent examples of related $\mathrm{C}-\mathrm{C}$-bonded atropisomeric derivatives of the bis-pyrrole type have been proposed independently by Bringmann's and Chmielewski's groups for the design of axially chiral BODIPY dyes 16 and 17 or of bis $(N$ confused porphyrin) $\mathbf{1 8}$ as a semirigid receptor with memory of chirality, respectively (Scheme 11). ${ }^{[24]}$

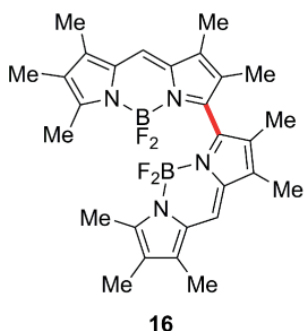

16

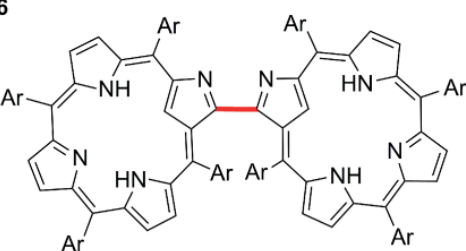

18<smiles></smiles>

17

Scheme 11. C-C-bonded atropisomeric BODIPY derivatives $\mathbf{1 6}$ and $\mathbf{1 7}$ and porphyrin derivative $\mathbf{1 8}$.

Finally, the imidazole nucleus has also been used to elaborate $C$-C-bonded atropisomeric 15- and 16-membered macrocycles 20a and $20 \mathrm{~b}$ from precursor 19 by ring-closing metathesis followed by hydrogenation. These macrocycles 20a and 20b show high barriers to rotation of 170.9 and $109.5 \mathrm{~kJ} \mathrm{~mol}^{-1}$, corresponding to half-lives of racemization at $25{ }^{\circ} \mathrm{C}$ of several trillion years and 40 days, respectively (Scheme 12). ${ }^{[25]}$

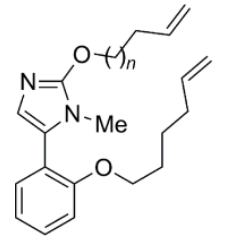

19
1) Grubbs-G2 (20 mol-\%) 2) $\mathrm{H}_{2}, \mathrm{Pd} / \mathrm{C}$

$75-81 \%$

20a, $n=1, \Delta G=170.9 \mathrm{~kJ} \cdot \mathrm{mol}^{-1}$ 20b, $n=2, \Delta G=109.5 \mathrm{~kJ} \cdot \mathrm{mol}^{-1}$

A new electroactive chiral polyheterocyclic organic film based on axially chiral C-C-bonded bithienyl assembies was designed and synthesized by Sannicolò's group. The racemic material was obtained by Stille coupling, and the two monomeric optically pure atropisomers (aR)-(-)-15 and (aS)-(+)-15 were obtained by separation on chiral HPLC and present a very high barrier to rotation of $167 \mathrm{~kJ} \mathrm{~mol}^{-1}$ (Scheme 10). ${ }^{[23]}$

Scheme 12. C-C-bonded atropisomeric 15- and 16-membered macrocycles 20a and 20b.

Since the first report of the axially chiral $\mathrm{C}-\mathrm{N}$-bonded arylpyrrole $\mathbf{5 a}$ in $1931,{ }^{[15]}$ the resolution of racemic mixtures either chemically or chromatographically has emerged as a central 
tool for the production of enantiomerically pure atropisomers containing five-membered rings. These have found numerous applications, notably in the design of metal complexes. Complementarily to these robust techniques, original stereoselective synthetic approaches have appeared during the two last decades and are presented in the following sections together with some specific applications of the resulting atropisomers.

\section{Stereoselective Syntheses}

\subsection{Diastereoselective Functionalizations of Axially Chiral Atropisomers}

The first representative, based on atropodiastereoselective desymmetrization of prochiral $\mathrm{N}$-arylmaleimide $\mathbf{2 1}$, is that of Curran et al. in 1994. ${ }^{[26 b]}$ They reasoned that the presence of a large ortho-tBu substituent should provide a high enough barrier towards rotation around the $\mathrm{C}-\mathrm{N}$ axis, for efficient stereoselective synthesis. Hence, the addition of a $t B u$ radical to $\mathbf{2 1}$ under the Giese conditions gave $\mathbf{2 4}$ with high diastereoselectivity (Scheme 13a, right). Alternatively, endo-selective Diels-Alder cycloaddition either with 2,3-dimethylbuta-1,3-diene at $80{ }^{\circ} \mathrm{C}$ or with cyclopentadiene at $25^{\circ} \mathrm{C}$ afforded the cycloadducts 25a and 25b with the same high diastereoselectivity (Scheme 13a, top). In addition, the authors demonstrated similar efficiency in 1,3-dipolar cycloaddition with neopentanenitrile oxide, although an important effect of the temperature on

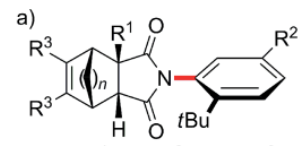

25a: $\mathrm{R}^{1}=\mathrm{H}, \mathrm{R}^{2}=t \mathrm{Bu}, \mathrm{R}^{3}=\mathrm{Me} ; n=0 ; 93: 7 d r$

25b : $\mathrm{R}^{3}=\mathrm{H} ; \mathrm{n}=1 ; 93: 7 d r$

25c $: \mathrm{R}^{1}=\mathrm{Me}, \mathrm{R}^{3}=\mathrm{R}^{2}=\mathrm{H}, n=1 ; 97: 3 d r, 96 \%$ ee

$$
25^{\circ} \mathrm{C} \text { to } 80^{\circ} \mathrm{C}
$$

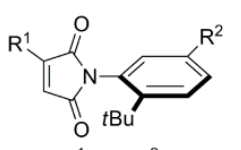

$$
\underset{\mathrm{NaBH}_{4}, 25^{\circ} \mathrm{C}}{\stackrel{t \mathrm{BuHgCl}}{\longrightarrow}}
$$

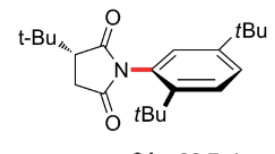

21: $R^{1}=H, R^{2}=t B u$

$22: R^{1}=M e, R^{2}=H$

$23: R^{1}=R^{2}=H$

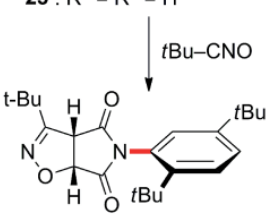

$26: 92: 8 d r$ at $-78^{\circ} \mathrm{C}$ $62: 38$ dr at $60^{\circ} \mathrm{C}$

b)
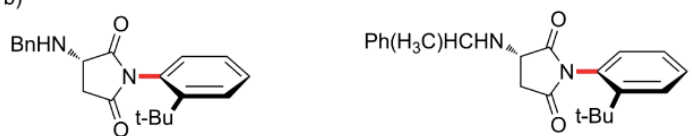

27b : >99:1 dr, $\Delta \mathrm{G}=119 \mathrm{~kJ} \cdot \mathrm{mol}^{-1}$ the

dia-

stereoselectivity was observed in the case of compound $\mathbf{2 6}$ (Scheme 13b, down arrow). Interestingly, and in agreement with their expectations, chiral compounds 24, 25a, and 26 were stable at room temperature and started to isomerize above $120{ }^{\circ} \mathrm{C}$, whereas $\mathbf{2 5 \mathbf { b }}$ never isomerized even at $150{ }^{\circ} \mathrm{C}$. At the same time, the Kishikawa group reported a related atropodiastereoselective amination of $\mathbf{2 3}$ affording the corresponding $\mathrm{N}$ benzyl- and $N$-(1-phenylethyl)succinimides 27a and 27b with diastereoselectivity ranging from 81:19 to $>99: 1 d r .^{[26 d]}$ The barriers to rotation were measured by ${ }^{1} \mathrm{H}$ NMR and were found to be around $120 \mathrm{~kJ} \mathrm{~mol}^{-1}$ for both atropisomers (Scheme 13b).

After these pioneering contributions with the prochiral $\mathrm{N}$ arylmaleimides 21-23, Taguchi and co-workers proposed a simple synthesis of axially chiral maleimide (+)-22 with $96 \%$ ee and a half-life for racemization of $15 \mathrm{~h}$ at $80{ }^{\circ} \mathrm{C}$ allowing its utilization in further stereoselective transformations (Scheme 14). ${ }^{[27 a]}$ The synthesis started from (R)-2-methylsuccinic acid (28) and ortho-tBu-aniline (29), followed by an oxidative selenoxide elimination from the resulting major diastereomer (1.3:1 dr) of succinimide $\mathbf{3 0}$ obtained with $96 \%$ ee after recrystallization. As expected from Curran's work, the thermal or Lewis-acid-catalyzed endo-selective Diels-Alder reaction between (+)-22 and cyclopentadiene proceeded with good yields and high diastereoselectivities to furnish 25c with 97:3 dr and $96 \%$ ee (Scheme 13a, top).

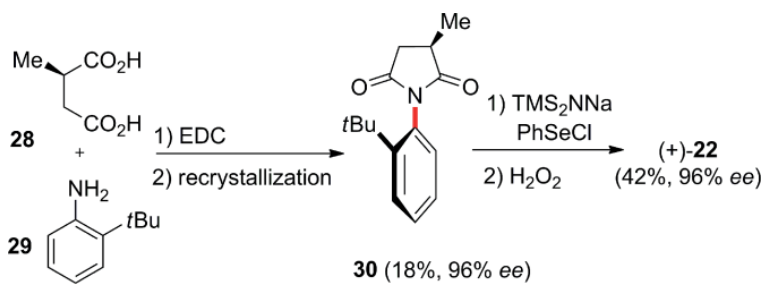

Scheme 14. Diastereoselective preparation of axially chiral maleimide (+)-22.

In a subsequent contribution, the same group disclosed an original three-step synthesis of $\mathbf{3 3}$, a new optically active axially chiral $\mathrm{N}$-arylpyrrolidone, with $\geq 98 \%$ ee from (S)-5-(methoxymethyl)butyrolactone (31) and aniline 29 (Scheme 15). ${ }^{[27 \mathrm{~b}]}$ Interestingly, the lithium enolate of $\mathbf{3 2}$ underwent diastereo-
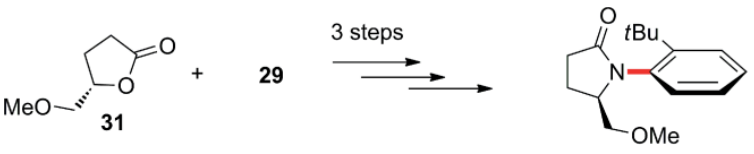

$32 \geq 98 \%$ ee

\begin{tabular}{llccc}
\multicolumn{1}{c}{ E-X } & E & xx & Yield (\%) & $\boldsymbol{d} \boldsymbol{r}$ \\
\hline $\mathrm{Bn}-\mathrm{Br}$ & $\mathrm{Bn}-$ & 33a & 98 & $10: 1$ \\
Davis reagent & $\mathrm{HO}-$ & 33b & 65 & $15: 1$ \\
& & & &
\end{tabular}

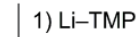

2) $\mathrm{E}-\mathrm{X}$ THF, $-95^{\circ} \mathrm{C}$

Allyl-Br

allyl- 33c 95

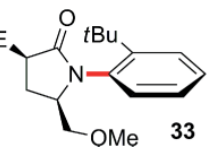

Scheme 15 . Diastereoselective axially chiral $\mathrm{N}$-arylpyrrolidones $\mathbf{3 2}$ and $\mathbf{3 3}$.

Scheme 13. Atropodiastereoselective desymmetrizations of maleimides 21 
selective functionalization with various electrophiles, leading to unusual 3,5-cis-disubstituted 2-pyrrolidinone derivatives 33 . Here also, the ortho-tBu group ensures a high barrier to rotation and shields the Si face of the enolate, resulting in the uncommon 3,5-cis selectivity. It is interesting to note that changing the $\mathrm{Bu}$ - group to a -OBn or even a -OTBDPS group resulted in free rotation around the $\mathrm{C}-\mathrm{N}$ axis at room temperature.

The usually high stereoselectivity found for cycloadditions has been exploited to access various families of original atropisomeric derivatives from easily accessible unsaturated precursors. For example, simple room-temperature-stable axially chiral $\mathrm{N}$-aryl-substituted monothiosuccinimides $\mathbf{3 4}$ were proposed by Sakamoto and collaborators in 2003 as interesting partners in chemo-, regio-, and diastereoselective [2+2] photocycloaddition to 1,1-diphenylethylene, leading to spirothietanes 35 in good yields (Scheme 16). ${ }^{[28]}$ In this transformation, the steric hindrance of the ortho-substituent was crucial and perfectly controlled the addition to form $\mathbf{3 5}$ exclusively.

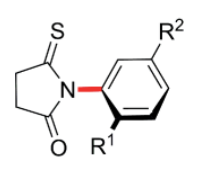

(S)-34
$\mathrm{R}^{1}=\mathrm{Me}, \mathrm{OMe}, \mathrm{Cl}$

$\mathrm{R}^{2}=\mathrm{H}, \mathrm{Me}$
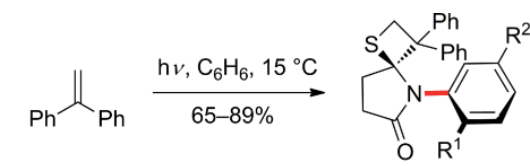

35
Scheme 16. Photocycloaddition of $\mathrm{N}$-aryl-substituted monothiosuccinimides 34.

In 2011 Savage's group reported an interesting atropisomeric facial selectivity during regioselective (1,3)-dipolar cycloaddition between benzonitrile oxide and racemic axially chiral $\mathrm{N}$ arylmethylenehydantoins $\mathbf{3 6}$ (Scheme 17). ${ }^{[29]}$ The nature of the ortho-substitution (R group) was crucial for the attainment of high diastereoselectivities, ranging from 2.5:1 to >99:1 ratios of anti-37 to syn-37. Interestingly, the best result was obtained with $\mathrm{R}=\mathrm{NO}_{2}$, leading to anti-37 only, probably due to additional electrostatic repulsion with the approaching nitrile oxide dipole.
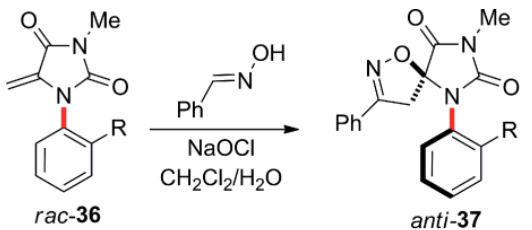

anti-37

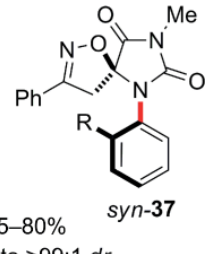

$.5: 1$ to $>99: 1 d r$
Scheme 17. (1,3)-Dipolar cycloaddition to $N$-arylmethylenehydantoins 36.

Also of interest is the reactivity of benzylidene $\mathrm{N}$-arylthiazolidinethiones 38, developed by Doğan's group as heterodiene partners in exo-selective inverse-electron-demand Diels-Alder cycloaddition with norbornene (Scheme 18). ${ }^{[30]}$ The cycloaddition proceeded smoothly to give the corresponding adducts 39a and $39 \mathrm{~b}$ at room temperature with a transient kinetic atroposelectivity of 11:1 $\left(R^{1}=B r, R^{2}=H\right)$, with equilibration after $24 \mathrm{~h}$ to the isolated thermodynamic ratio of 2:1 in favor of 39a, regardless of the substitution patterns. This phenome- non is due to a quite significantly lower barrier to rotation for the adducts $\mathbf{3 9}$ than for the starting heterodienes $\mathbf{3 8}$, by about $20 \mathrm{~kJ} \mathrm{~mol}^{-1}$.
(1)

38, $\mathrm{R}^{1}=\mathrm{OMe}, \mathrm{R}^{2}=\mathrm{H}$ $\Delta G=115.9 \mathrm{~kJ} \cdot \mathrm{mol}^{-1}$

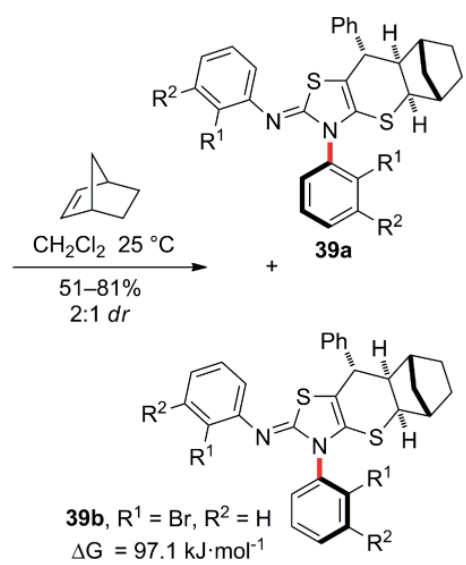

$\Delta \mathrm{G}=97.1 \mathrm{~kJ} \cdot \mathrm{mol}^{-1}$
Scheme 18. exo-Selective hetero-Diels-Alder cycloaddition of $\mathrm{N}$-arylthiazolidinethiones $\mathbf{3 8}$.

Complementarily to cycloadditions, simple chemical transformation of $\mathbf{N}$-arylindole $\mathbf{4 0}$ was used by Nakazaki and collaborators to prepare the stable chiral nonracemic $N$-arylisatin 41 , obtainable in optically pure form by chiral HPLC and featuring a barrier to rotation of $130 \mathrm{~kJ} \mathrm{~mol}^{-1}$ (Scheme 19). ${ }^{[1]]}$ The racemic 41 constituted an interesting synthetic starting material for obtaining functionalized $\mathrm{N}$-aryloxindole derivatives 42 through diastereoselective nucleophile additions, alkylations, and cycloadditions.

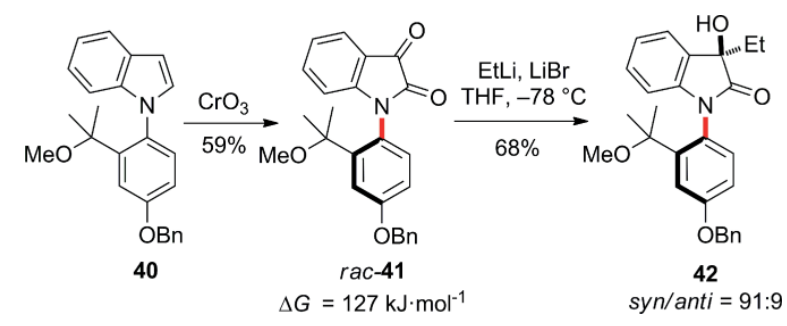

Scheme 19. Axially chiral $\mathrm{N}$-arylindole, -isatin and -oxindole atropisomers $\mathbf{4 0}$ 42.

Utilization of enantiopure precursors was reported by Sivaguru's group in the photochemical type II cyclization of nonbiaryl atropisomeric benzoylformamides $\mathbf{4 3}$ to afford $\mathrm{N}$-aryloxazolidinones 44 (Scheme 20a). ${ }^{[32]}$ The cyclization proceeds with chiral memory, resulting in the preservation of the configuration of the $\mathrm{C}-\mathrm{N}$ chiral axis with the concomitant creation of one stereogenic center with an average of 66:34 $d r$ and $\geq 86 \%$ ee for each syn and anti diastereomer. Their mechanistic experiments argue for lower barriers to rotation in $\mathrm{N}$-aryloxazolidinones $\mathbf{4 4}$ than in the starting benzoylformamides $\mathbf{4 3}$, as corroborated by the thermally induced atropisomerization of optically pure anti-44 in favor of the corresponding ent-syn-44 photoproduct without the $\mathrm{C}-5$ stereogenic center being affected (Scheme 20b). 
a)<smiles>[R]c1ccc(C(C)(C)Br)c(N(C(=O)C(=O)c2ccccc2)C2CNC2)c1</smiles>

$(+)$ - or $(-)-43$

$n=0,2,3$

$\mathrm{R}=\mathrm{H}, \mathrm{Me}$

b)

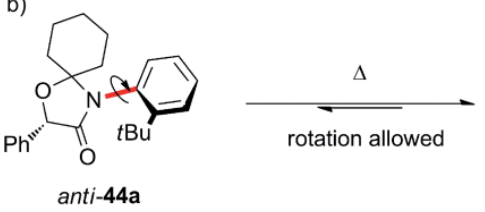

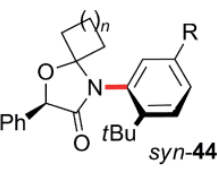

$\sim 66: 34 d r$

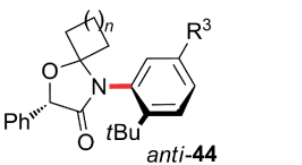

Scheme 20. Photochemical synthesis and atropisomerization of $\mathrm{N}$-aryloxazolidinones 44

\subsection{Diastereoselective Construction of the Stereogenic Chemical Bond}

The direct stereoselective construction of the axially chiral bond constitutes a challenging synthetic task and only few examples have been proposed to date. A simple transamidation approach between pyromellitic dianhydride (45) and 2-amino-3-methylbenzoic acid, giving access to the expected atropisomeric diacids as a 1:1 mixture of syn and anti conformers 46, was disclosed by Shimizu's group (Scheme 21a). ${ }^{[33]}$ Both atropisomers were found to be stable at room temperature, as illustrated by calculated $\Delta G^{\ddagger}$ values of 122.9 to $142.1 \mathrm{~kJ} \mathrm{~mol}^{-1}$, and have different hydrogen-bonding affinities toward ethyl adenine-9-acetate (47) as a guest. This was exploited to devise new thermally induced conformationally imprinted receptors with "write, save, and erase" recognition properties. This is shown by selective $\mathrm{H}$ bonding interactions between $\mathbf{4 7}$ and syn-46 at $90{ }^{\circ} \mathrm{C}$ ("write") and release of the guest molecule upon cooling to room tem-
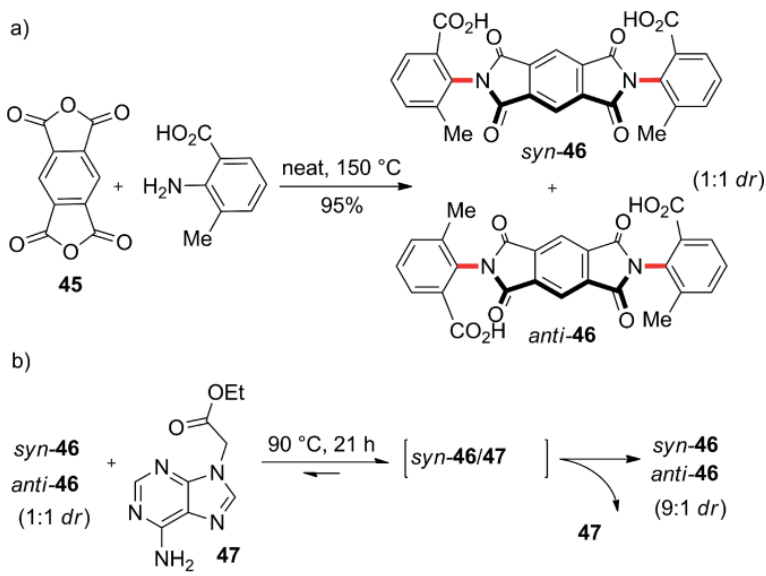

Scheme 21. Stable syn- and anti-atropisomeric diacids $\mathbf{4 6}$ as imprinted receptors.

perature, resulting in a large increase in the diastereomeric ratio (1:1 to 9:1 dr) in favor of syn-46 ("save"), due to the restricted rotation around the $C-N$ axes (Scheme $21 \mathrm{~b}$ ). Finally, the 1:1 syn/anti ratio can be restored by heating ("erase") the 9:1 mixture in the absence of the guest.

More recently, Doğan reported the atropodiastereoselective synthesis of axially chiral thiohydantoin derivatives $\mathbf{4 9}$ through the reaction between amino acid ester salts and o-arylisothiocyanates $\mathbf{4 8}$ in the presence of a base (Scheme 22). ${ }^{[34]}$ Moderate diastereoselectivities were achieved and could be increased by recrystallization. Bulky substituents $\mathrm{R}^{3}$ were necessary to avoid racemization of the stereogenic center during the heterocyclization step.

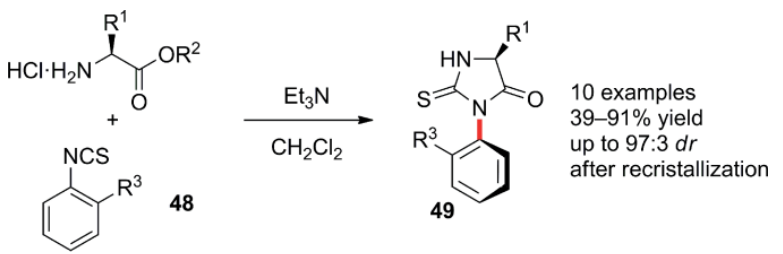

Scheme 22. Atropodiastereoselective synthesis of thiohydantoins $\mathbf{4 9}$

Very recently, Wencel-Delord and Colobert reported elegant intermolecular atropodiastereoselective $\mathrm{C}-\mathrm{N}$ bond cross-coupling between indolines and optically pure chiral sulfoxide iodanes $\mathbf{5 0}$ (Scheme 23 ). ${ }^{[35]}$ The use of these highly electrophilic coupling partners allowed this $\mathrm{Cu}^{\prime}$-catalyzed $\mathrm{C}-\mathrm{N}$ bond Ullmann-type coupling to be performed at low temperature, ensuring the configurational stability of atropisomers $\mathbf{5 1}$. The use of the sulfoxide function as a traceless auxiliary is interesting because many post-functionalizations are available. As an example, the atropisomer 51a was converted into axially chiral aldehyde $\mathbf{5 2}$ with complete retention of $\mathrm{C}-\mathrm{N}$ bond stereogenicity.

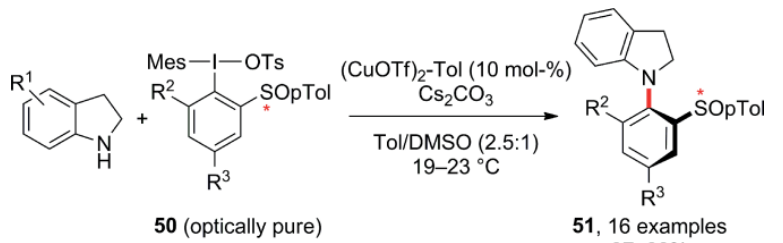
1, 16 examples $37-99 \%$ $89: 11$ to $>95: 5 d r$

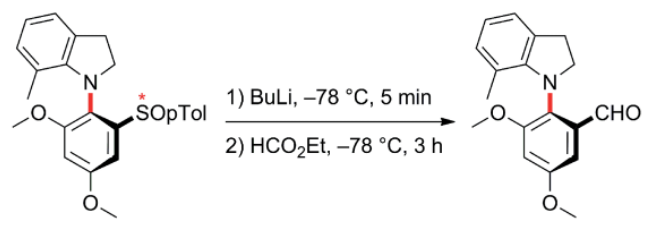

$51 \mathrm{a}$

52, $50 \%, 96 \%$ ee

Scheme 23. Atropodiastereoselective $C-N$ bond cross-coupling reaction.

\subsection{An Update on Enantioselective Approaches}

This more appealing but highly challenging alternative emerged at the beginning of the last decade and has attracted 
strong recent interest, notably with the development of organocatalytic transformations. It includes complementary strategies based on both stoichiometric and catalytic enantioselective methods, starting variously with simple achiral, prochiral, or racemic precursors, which have been comprehensively reviewed very recently. ${ }^{[36]}$ Therefore, the next section offers an update of this growing field, presenting the small number of very recent and elegant approaches that allow direct enantioselective access to axially chiral five-membered atropisomers.

Tong and co-workers have recently proposed two complementary examples based on the strategy developed in our group $^{[37]}$ for the enantioselective synthesis of furan atropisomers through oxidative central-to-axial chirality conversion (Scheme 24). ${ }^{[38]}$ The optically active dihydronaphthofuran precursors $54 \mathrm{a}$ and $\mathbf{5 4 b}$ were obtained by enantioselective phosphine-catalyzed $(3+2)$ annulation of $\delta$-acetoxy allenoates $\mathbf{5 3}$ with 2-naphthols. Subsequent DDQ oxidation resulted in total conversion of chirality in the case of $\mathbf{5 5 a}$, whereas a slight enantiomeric erosion was observed with $\mathbf{5 5} \mathbf{b}$, probably due to its lower barrier to rotation and the relatively high temperature necessary for oxidation.
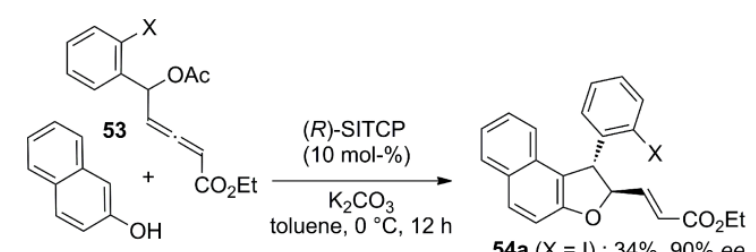

54a $(X=1): 34 \%, 90 \%$ ee 54b $(X=M e): 93 \%, 88 \%$ ee

(R)-SITCP =
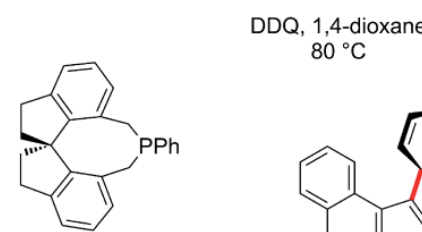

$$
80^{\circ} \mathrm{C}
$$

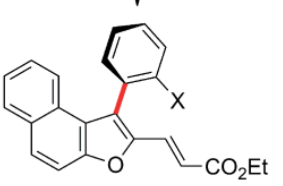

55a $(X=1): 47 \%, 90 \%$ ee 55b $(X=M e): 63 \%, 70 \%$ ee

Scheme 24. Enantioselective synthesis of furan atropisomers $\mathbf{5 5}$ by a centralto-axial chirality conversion.

In their outstanding quest for new enantioselective atroposelective reactions, Tan and co-workers ${ }^{[39]}$ disclosed a particularly elegant and general organocatalytic method for arylation of indoles (Scheme 25). They found that the azo function acts both as a directing and as an activating group for the nucleophilic aromatic substitution of azobenzene derivatives $\mathbf{5 6}$ with indoles. When $R^{3}$ is a hindered alkyl group, the presence of chiral phosphoric acid $\mathbf{5 7}$ allows the synthesis of indole derivatives $\mathbf{5 8}$ with excellent yields and enantioselectivities, through the formation of intermediates $\mathbf{6 1}$ that quickly aromatize by proton elimination. The authors serendipitously discovered that when the $\mathrm{R}^{3}$ substituent is less bulky (Me or $\mathrm{Pr}$ ), the intermediates $\mathbf{6 1}$ evolve differently and cyclize by intramolecular addition to the iminium ion to generate pentacyclic intermediates $\mathbf{6 2}$. After $\beta-\mathrm{H}$ elimination and cleavage of the $C-N$ bond, the atropisomers $\mathbf{6 0}$ are obtained in good yields and with excellent enantioselectivities. Interestingly, in this last transformation, only 0.2 mol- $\%$ of chiral phosphoric acid $\mathbf{5 9}$ is necessary, showing the high efficiency of this catalyst in this case.

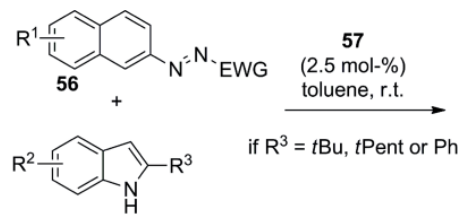

59
$\begin{gathered}0.2 \mathrm{~mol}-\%) \\ \text { DCM, r.t. }\end{gathered}$<smiles>[R][R]1ccc2ccc3c(c(-c4cccc[R]4[R])c([R])n3NC(C)=O)c2c1</smiles>

\section{0, 20 examples} $45-88 \%$

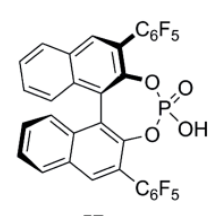

57<smiles></smiles>

58, 23 examples $84-98 \%$ $80-99 \%$ ee

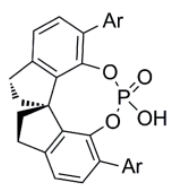

59, $\mathrm{Ar}=9$-phenanthryl

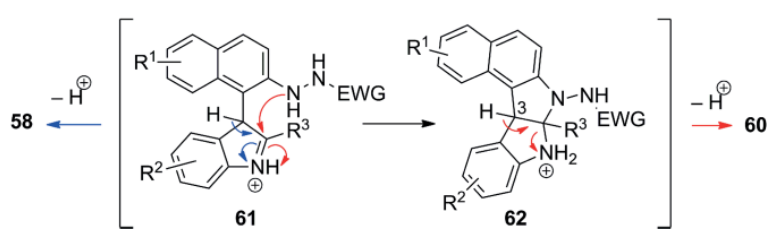

Scheme 25. Organocatalytic enantioselective arylation of indoles.

Finally, Bencivenni's group developed organocatalyzed enantioselective Friedel-Crafts alkylation between inden-1-ones $\mathbf{6 3}$ and 2-naphthols 64, giving rise to a not so common class of atropisomers each displaying a stereogenic $C\left(s p^{3}\right)-C\left(s p^{2}\right)$ bond (Scheme 26). ${ }^{[40]}$ Quinidine derivative 65 was used as the organocatalyst, and bulky $\mathrm{R}^{2}$ substituent were necessary to achieve high enough barriers to rotation. In this transformation, the steric hindrance generated during the creation of the stereogenic bond, combined with the presence of the stereogenic carbon atom, govern the distribution in favor of the $a p$ diastereomeric conformer, through thermodynamic control.

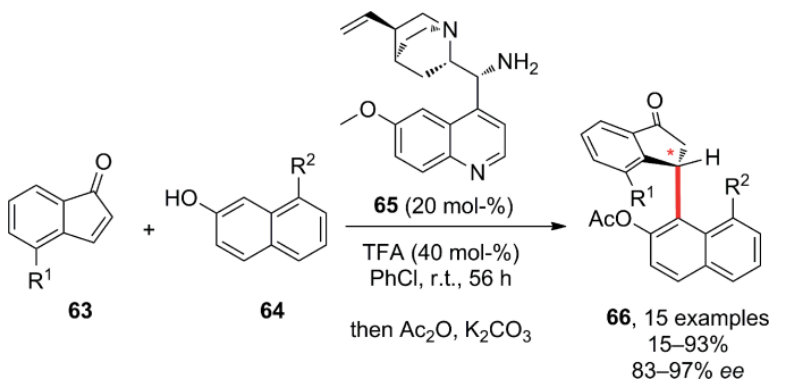

Scheme 26. Organocatalytic enantioselective construction of $C\left(s p^{3}\right)-C\left(s p^{2}\right)$ atropisomers 66 .

\section{As Ligands for Metal Complexes}

An important application for atropisomers displaying five-membered rings is their utilization as ligands for metals. This may 
involve either axially chiral $\mathrm{C}-\mathrm{N}$ - or $\mathrm{C}$ - $\mathrm{C}$-bonded five-membered heterocyclic rings. Chauvin's group, for example, reported comprehensive studies on the synthesis, resolution, and applications in enantioselective catalysis of atropochiral $\mathrm{C}-\mathrm{N}$-bonded $\mathrm{N}$-naphthylimidazolylphosphine BIMINAP-67a and its corresponding $\mathrm{N}$-methylated cation BIMIONAP-67b as new diphosphane ligands with similar chelating properties for palladium, leading to the corresponding Pd" complexes $67 \mathrm{c}$ and $\mathbf{6 7 d}$ (Scheme 27). ${ }^{[41 \mathrm{a}, 41 \mathrm{~b}]}$ Interestingly, (aR)-(+)-67a, obtained by fractional crystallization of the $(R)-\alpha$-naphthylethylamine $\mathrm{Pd}$ " complexes, proved to be an efficient ligand for the enantioselective Tsujii-Trost allylation of dimethyl malonate. ${ }^{[41 b]}$<smiles>Pc1cccc(-n2c(-c3ccccc3)nc3ccccc32)c1-c1ccccc1</smiles>

(aR)-(+)-BIMINAP-67a<smiles></smiles>

$( \pm)$-BIMIONAP-67b<smiles></smiles>

67c : $\mathrm{E}=$ lone pair 67d : $\mathrm{E}=\mathrm{Me}^{\oplus}, \mathrm{TfO}^{\ominus}$
Scheme 27. $C-N$-bonded atropisomeric $N$-naphthylimidazolylphosphine ligands $67 \mathrm{a}$ and $67 \mathrm{~b}$ and their Pd" complexes 67c and $67 \mathrm{~d}$.

Interestingly, the related atropisomeric $\mathrm{N}$-arylindoline-type aminophosphine 68a, introduced by Mino and collaborators in 2006 and also obtained by optical resolution from their palladium(II) complexes, and the corresponding oxidized $\mathrm{N}$-arylindole $\mathbf{6 8} \mathbf{b}$ proved to be efficient ligands for enantioselective allylic alkylation catalyzed by $\mathrm{Pd}^{0}$ with either malonates or indoles as nucleophilic partners (Scheme 28). ${ }^{[42]}$<smiles>CC(=O)OCc1cccc(-c2ccccc2)c1N1CCc2ccccc21</smiles>

(aS)-68a

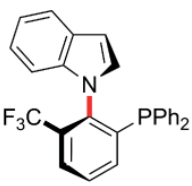

(aS)-68b

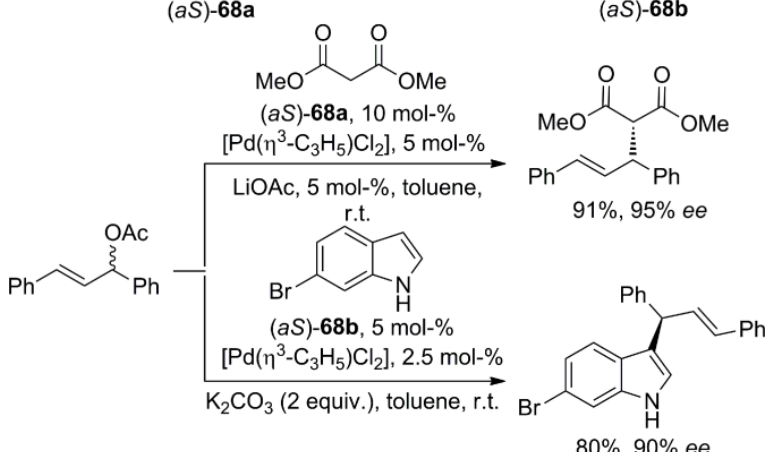

Scheme 28. $\mathrm{N}$-Arylindoline and $\mathrm{N}$-arylindole chiral atropisomeric ligands $\mathbf{6 8 a}$ and $\mathbf{6 8 b}$.

Complementary contributions in the field of organometallic catalysis appeared soon after and involve $\mathrm{C}-\mathrm{N}$-bonded atropisomeric 1- $N$-phenylpyrrole-derived amino alcohols of type 69b proposed by Faigl's group for the efficient enantioselective addition of diethylzinc to arylaldehydes (Scheme 29). ${ }^{[43]}$ The optically active 1-phenylpyrrole-2-carboxylic acid precursor 69a was obtained by resolution with $(R)$-methylbenzylamine and also served both as a chiral discriminating agent in enantiomeric excess determination with different chiral amines and for derivatizations to other atropisomers. ${ }^{[4]}$ The presence of the pyrrolidine ring resulted in greatly improved ee values in relation to other previously developed $\mathrm{N}$-alkyl ligand analogues of $69 b^{[43 a-43 d]}$ ranging from $88 \%$ to $95 \% .^{[43 e]}$<smiles>OC(c1ccccc1)(c1ccccc1)c1cccc(C(F)(F)F)c1-n1cccc1CN1CCCC1</smiles>

$(a S)-(+)-69 b$

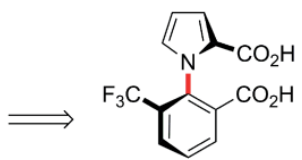

(aS)-(+)-69a

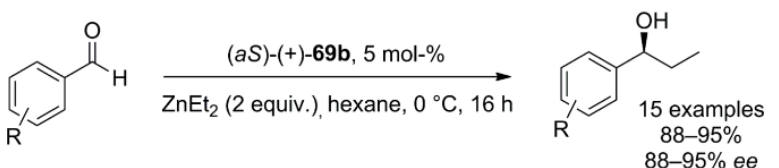

Scheme 29. Enantioselective addition of $\mathrm{ZnEt}_{2}$ in the presence of 1-phenylpyrrole ligand 69b.

Enantioenriched arylsuccinimide $\mathbf{7 2}$ was obtained by Shimizu and collaborators by means of a transamidation strategy with simple succinic anhydride $\mathbf{7 0}$ and aminophosphine 71 coupled with a chemical resolution. This new axially chiral phosphine ligand gave only moderate enantioselectivity in $\mathrm{Pd}^{0}$-catalyzed allylic alkylation (Scheme 30$) .{ }^{[45]}$

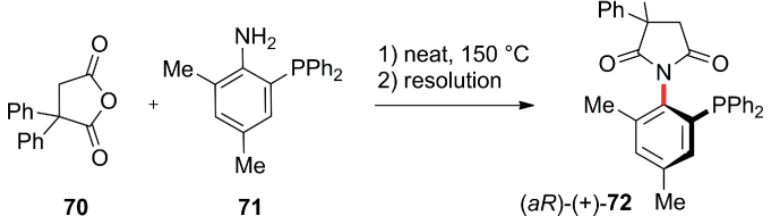

Scheme 30. Preparation of axially chiral $\mathrm{N}$-arylphosphinosuccinimide ligand 72.

Another very important family of $\mathrm{C}-\mathrm{N}$-bonded non-biaryl atropisomers incorporating five-membered rings is that of $\mathrm{N}$ arylazolium salts $\mathbf{7 3}$, precursors of $\mathrm{N}$-heterocyclic carbenes (NHCs) 74, which have found many important applications in catalysis either as ligands or as catalysts (Scheme 31). ${ }^{[46]}$

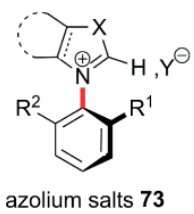

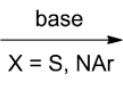

azolium salts 73

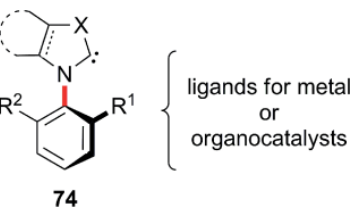

74
Scheme 31. Axially chiral $\mathrm{N}$-arylazolium salts $\mathbf{7 3}$ and $\mathrm{N}$-aryl-NHCs $\mathbf{7 4}$.

In this field, the independent pioneering contributions by the Grubbs and Hoveyda groups in designing new chiral nonracemic precatalysts for olefin metathesis have inspired further interesting developments. ${ }^{[4]}$ Their strategies are based on diastereoselective synthesis of optically pure Ru-NHC complexes, securing atropochiral stability of ortho- $\mathrm{N}$-phenyl- or 
$N$-naphthyl substituents. However, because of relatively low barriers to rotation the situation becomes difficult to manage with the corresponding azolium salt precursors and even more so when the free carbene ligands are considered. In this context, the first insights into obtaining axially chiral azolium salts and their carbene analogues were reported in 2004 by Bach's group (Scheme 32). ${ }^{[48]}$ The most promising result involves the diastereoselective synthesis of optically pure $\mathrm{N}$-phenylthiazolium salt 75, a precursor of the corresponding thiazolylidene-NHCs $\mathbf{7 6}$ evaluated as catalysts in model benzoin and Setter condensations. The synthesis started with the condensation of ortho-tBu-aniline (29) with $\alpha$-bromomenthone in the presence of $\mathrm{CS}_{2}$, followed by cyclodehydration and subsequent oxidation (Scheme 32a). Although $\mathbf{7 5}$ proved to be configurationally stable at room temperature, the modest $40 \%$ and $50 \%$ ee values obtained for benzoin and Stetter reactions, respectively, suggested substantial $(75: 25 d r)$ atropisomerization of the corresponding NHCs 76 generated in situ (Scheme 32b).

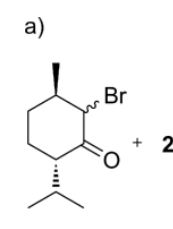

1) $\mathrm{NaOH}, \mathrm{CS}_{2}$, DMSO

2) $\mathrm{HCl}$, pentane

3) $\mathrm{MeSO}_{3} \mathrm{H}, \mathrm{EtOH}$, reflux

4) $m$-CPBA, $\mathrm{HClO}_{4}, \mathrm{THF},-78{ }^{\circ} \mathrm{C}$

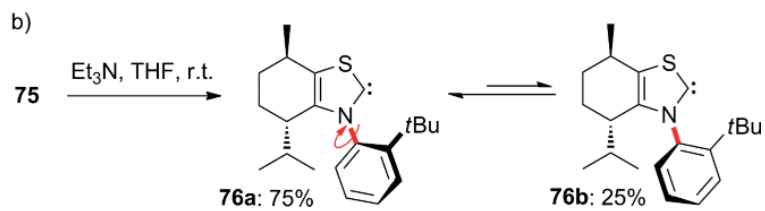

Scheme 32. Axially chiral N-phenylthiazolium salt 75 and $\mathrm{N}$-phenyl-NHCs 76

At the same time, Helmchen proposed 77, an axially chiral $\mathrm{N}$-naphthyl ortho-diphenylphosphinoimidazolium salt precursor of the chiral Rh complex 78, which proved to be an efficient promotor of enantioselective catalytic hydrogenation of $\alpha, \beta$-unsaturated esters, with up to $99 \%$ ee (Scheme 33). ${ }^{[49]}$ Interestingly, 77, easily obtained in 87:13 $d r$ from $(S, S)$-1,2-diphenylethylene-1,2-diamine, proved to be conformationally stable up to $135^{\circ} \mathrm{C}$, indicating a high barrier to rotation around the stereogenic $C-N$ axis.

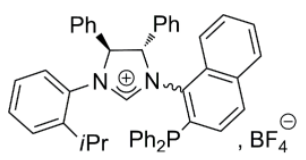

$77,87: 13 d r$

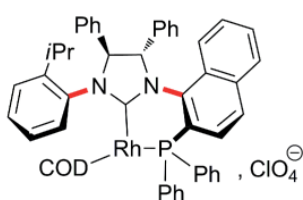

Scheme 33. Axially chiral $N$-naphthyl ortho-diphenylphosphinoimidazolium salt $\mathbf{7 7}$ and Rh complex $\mathbf{7 8 .}$

After those reports, Dorta and collaborators showed that the preparation of imidazolium salts $\mathbf{8 0}$ from the corresponding ethane-1,2-diamines 79, bearing alkyl substituents ( $\mathrm{Me}, i \mathrm{Pr}, \mathrm{Cy}$ ) on the naphthyl moiety, resulted in the diastereoselective formation of (anti)- $C_{2}$-symmetric and (syn)-meso atropisomers in ratio ranging from 1.1:0.9 to $3: 1$ (Scheme 34). ${ }^{[50]}$ Whereas fast rotation was observed for the unsubstituted imidazolium salt $\left(R^{1}=R^{2}=R^{3}=H\right)$ even at $-90{ }^{\circ} \mathrm{C}$, introduction of Me or $i \mathrm{Pr}$ substituents at the crucial $R^{1}$ position needed temperatures higher than $96{ }^{\circ} \mathrm{C}$ for interconversion to be observable. With $\mathrm{R}^{1}=\mathrm{Cy}$, both diastereomers were found to be stable up to $126^{\circ} \mathrm{C}$.

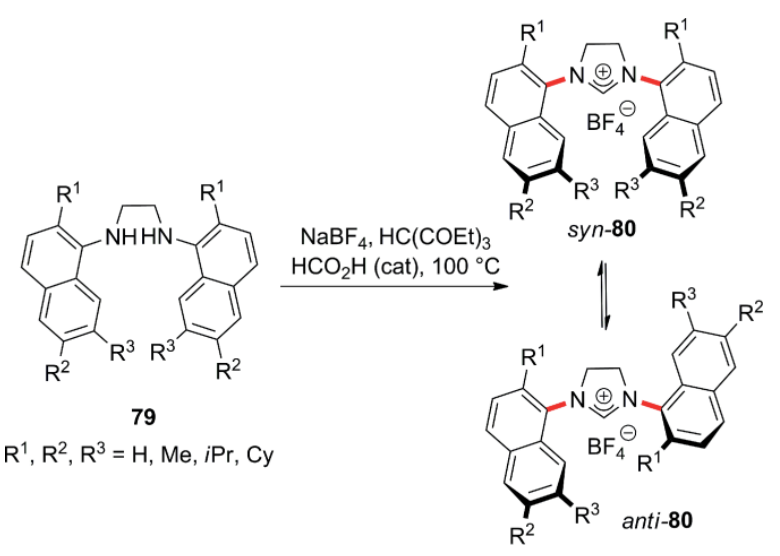

Scheme 34. Axially chiral $\mathrm{N}, \mathrm{N}$-dinaphthylimidazolium salts $\mathbf{8 0}$.

Interestingly, base-promoted deprotonation of $\mathbf{8 0}$ allowed the identification of $\mathbf{8 1}$, a new family of stable free monomeric imidazolinylidene NHCs incorporating two identical substituted naphthyl moieties on each nitrogen atom (Scheme 35). However, when $R^{1}=M e$, the atroposelectivity was lost for $\mathbf{8 1}$ at room temperature, but it was totally maintained with $\mathrm{R}^{1}=i \mathrm{Pr}$ or $\mathrm{Cy}$, rendering the same ratio of anti-81 and syn-81 atropisomeric NHCs. This result clearly argues for preserved high rotation barriers even after removal of the imidazolinium proton. In all cases the activation free energies $\left(\Delta G^{\ddagger}\right)$ of atropisomerization for salts $\mathbf{8 0}$ and NHCs $\mathbf{8 1}$ were determined by variable-temperature NMR analyses, showing values from 44 to $90 \mathrm{~kJ} \mathrm{~mol}^{-1}$ and an average decrease of $20 \mathrm{~kJ} \mathrm{~mol}^{-1}$ after deprotonation. ${ }^{[50 \mathrm{~b}]}$ Complementarily, the authors demonstrated the efficient ligand ability of this new family of NHCs, which was comparable with that of other widely used congeners, showing good catalytic
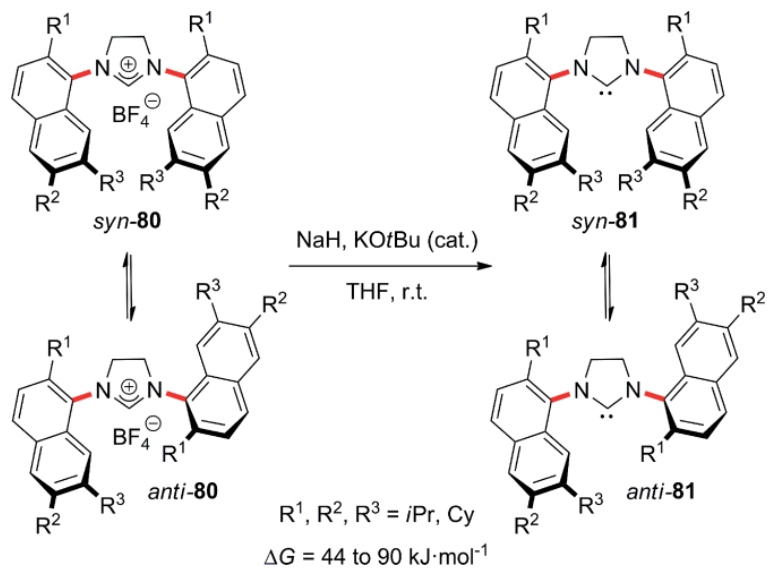

Scheme 35. Axially chiral N,N-dinaphthylimidazolinylidene NHCs 81. 
activities in Ru-, Pd-, or Al-catalyzed transformations such as ring-closing metathesis, Suzuki-Miyaura cross-coupling, Hartwig-Buchwald amination, and alkylative ring-opening of epoxides.

More recently, axially chiral NHCs of the $\mathrm{N}$-naphthylbenzimidazole series have been the subject of detailed experimental and theoretical studies by Chauvin and collaborators (Scheme 36). ${ }^{[51 a, 51 b]}$ They have clearly established that enantiopure axially chiral NHCs $\mathbf{8 2}$, derived from the two enantiomers of imidazolium ions $\mathbf{6 7 b}$ by dephosphorylation, are configurationally stable, leading to the isolation of the two corresponding enantiomeric Pd complexes $\mathbf{8 3}$.

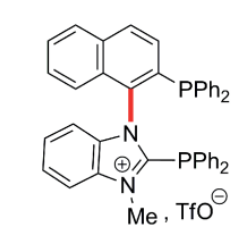

(+)- or (-)-BIMIONAP-67b

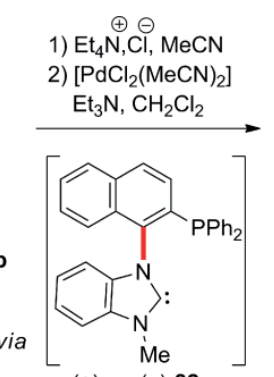

$(+)-$ or $(-)-82$

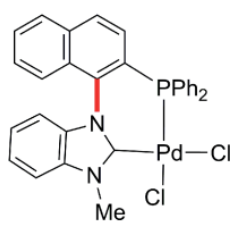

$(+)$ - or $(-)-83$
Scheme 36. Axially chiral $\mathbf{N}$-naphthylbenzimidazolinylidene NHCs 82 and its Pd complex 83.

Concurrently, the group of Wang and Shi designed the new related $\mathrm{Pd}$ complex $(a S, S)-\mathbf{8 4}$, featuring a chiral nonracemic oxazoline ligand instead of the $-\mathrm{PPh}_{2}$ one. It was found to be efficient for catalytic enantioselective allylic arylation, resulting in the kinetic resolution of Morita-Baylis-Hillman adducts (Scheme 37). ${ }^{[51 \mathrm{c}]}$

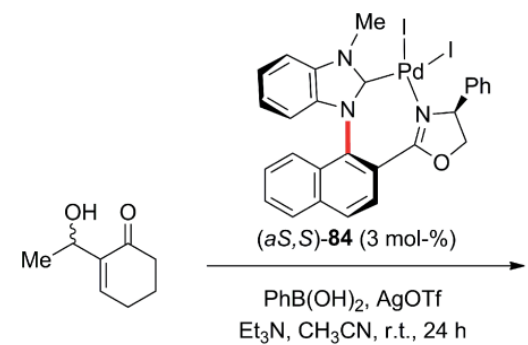

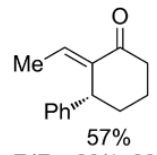

$E / Z=99 / 1,99 \%$ ee
Scheme 37. Enantioselective allylic arylation with Pd complex 84.

The resolution approach has also been exploited to obtain chiral nonracemic atropisomers featuring interesting properties as new ligands for transition-metal catalysis, intensively developed by the Sannicolò group at the end of the 1990s. ${ }^{[52]}$ An interesting example can be found in the straightforward synthesis of 3-arylbenzothiophene derivatives such as $\mathbf{8 5}$ by fractional crystallization of the diastereomeric adducts from $(R)$ - or $(S)$ O,O'-dibenzoyltartaric acid (Scheme 38). ${ }^{[53]}$ The authors showed the excellent behavior of this atropisomeric diphosphine as ligand either for Ru-catalyzed enantioselective hydrogenation or for Pd-catalyzed Diels-Alder cycloaddition.
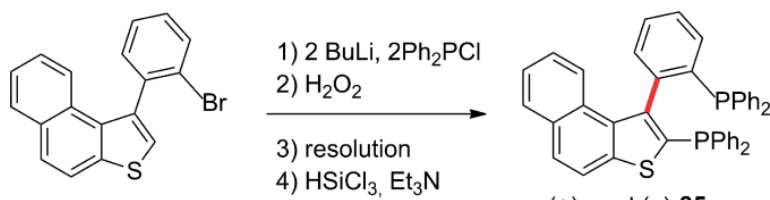

(+)- and (-)-85

Scheme 38. Enantiomerically pure 3-phenylbenzothiophene diphosphines 85

Related atropisomeric diphosphine derivatives, each containing two axially chiral $\mathrm{C}-\mathrm{C}$-bonded five-membered heterocyclic rings, are also easily available by the same resolution protocol. This is exemplified by the preparation of the two stable enantiomers of bithiophene $\mathbf{8 6 a}$ and of those of bibenzothiophene 86b (Scheme 39). This new family of atropisomers proved to be efficient ligands for the enantioselective Ru-catalyzed hydrogenation of unsaturated esters and 1,3-dicarbonyl compounds ${ }^{[54 a-54 c]}$ or for inter- and intramolecular Heck reactions. ${ }^{[55]}$<smiles>Cc1sc(C)c(-c2c(C)sc(C)c2-c2ccccc2)c1-c1ccccc1</smiles>

$(a R)-(+)-$ and $(a S)-(-)-86 a$

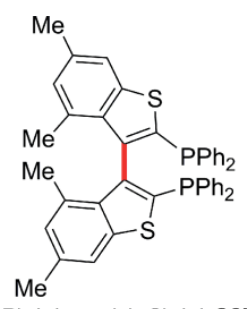

$(a R)-(+)-$ and $(a S)-(-)-86 b$
Scheme 39. Axially chiral bithiophene and bibenzothiophene ligands $\mathbf{8 6 a}$ and $\mathbf{8 6 b}$, respectively.

The bibenzofuran analogue was found to be configurationally unstable, ${ }^{[54 c]}$ but the corresponding bis-diphenylphosphine binaphthofuran BINAPFu (87) could be successfully prepared and resolved with (S)-camphorsulfonyl azide through a Staudinger reaction. ${ }^{[56]}$ It was then found that this new ligand outperformed BINAP in the Heck reaction between phenyl triflate and 2,3-dihydrofuran (Scheme 40).

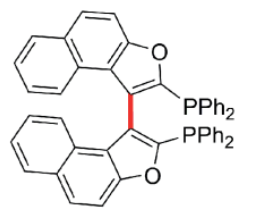

$(a R)-(+) /(a S)-(-)-B I N A P F u-87$

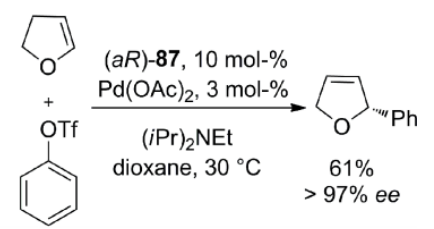

Scheme 40. Bibenzofuranyl phosphine $\mathbf{8 7}$ as a chiral atropisomeric ligand.

Complementarily to this new series of chiral atropisomeric phosphine ligands, the C3-C3-bonded $\mathrm{NH}$-biindolyl analogue $\mathbf{8 8} \mathbf{a}^{[54 \mathrm{~d}]}$ and the corresponding $\mathrm{C2}-\mathrm{C2}$-bonded $\mathrm{N}$-alkyl-biindoles BIMPs-88b and $\mathbf{- 8 8} c^{[54 e, 54 f]}$ were obtained enantiomerically pure by resolution from chiral palladium complexes or tartaric acid adducts, respectively (Scheme 41a). Similarly, BIMIP$\mathbf{8 9} \mathbf{a}^{[54 \mathrm{e}, 54 \mathrm{~g}]}$ a unique example of an axially chiral $N-N$-bonded bibenzimidazole atropisomer, could be obtained in enantiomerically pure form by resolution of the corresponding $(R)$ - or (S)-dimethyl naphthylethylamine palladium complexes or by 
separation by chiral HPLC (Scheme 41b). All of these unconventional diphosphines have been evaluated as ligands, with variable efficiencies, in either Pd"- or Pt"-catalyzed Diels-Alder cycloadditions. ${ }^{[54 \mathrm{~h}]} \mathrm{A}$ similar resolution approach was used to prepare $C$-naphthylbenzimidazole $P, N$-bidentate ligand $(a S)-(-)-$ BIMNAP-89b. ${ }^{[54 i]}$<smiles></smiles>

(aS)-(-)-88a

b)

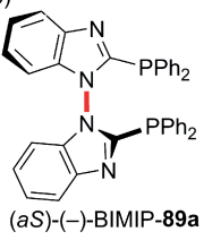

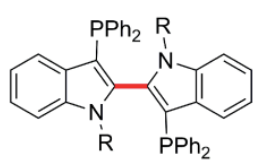

$\mathrm{R}=\mathrm{Me}, \mathrm{CH}_{2} \mathrm{OMe}$

$(+)$ - and (-)-BIMPs-88b,c

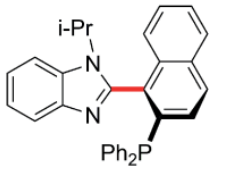

(aS)-(-)-BIMNAP-89b

Scheme 41. C3-C3- and C2-C2-bonded biindolyls 88a-c, $N-N$-bonded bibenzimidazolyl $\mathbf{8 9}$ a, and $C$-naphthyl-bonded benzimidazolyl $\mathbf{8 9}$ b.

An original design for a chiral biaryl $\mathrm{P}, \mathrm{N}$-ligand was introduced by Aponick's group in 2013 (Scheme 42a). ${ }^{[57 a]}$ They prepared the imidazole-based biaryl $P, N$-ligand $\mathbf{9 0}$ in six steps from commercially available 2-hydroxy-1-naphthaldehyde. Two additional steps, including a highly diastereoselective complexation with a chiral palladium complex, followed by decomplexation with dppe, allowed its deracemization (isolated in $98 \%$ ee). The barrier to rotation of $\mathbf{9 0}$ is increased by a favorable intramolecular $\pi$-stacking interaction that stabilizes the chiral ground-state conformation. This ligand, named Stackphos, was found to be particularly efficient not only in enantioselective coppercatalyzed aldehyde-alkyne-amine coupling (A3-coupling), but

a)<smiles>O=Cc1c(O)ccc2ccccc12</smiles>

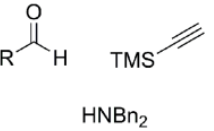

b)<smiles>FC(F)(F)Cn1c(-c2ccccc2)nc(-c2ccccc2)c1-c1ccc2ccccc2c1-c1ccccc1</smiles>

Scheme 42. Aponick's five-membered-ring-containing atropisomeric $P, N$-ligands 90 and 91. also in quinoline alkynylation, ${ }^{[57 b]}$ the synthesis of skipped diynes, ${ }^{[57 c]}$ and the conjugate alkynylation of Meldrum's acid acceptors. ${ }^{[57 d]}$

Building on this new strategy for increasing the barrier to rotation, the same group, as well as Guiry's group, introduced axially chiral phosphino-imidazoline ligands 91 , also featuring central chirality (Scheme 42b). ${ }^{[58]}$ The synthesis is more efficient, notably avoiding the use of stoichiometric amounts of chiral palladium complex for the deracemizing step. In this case, the resolution was achieved by fractional crystallization. This ligand was found also to be very efficient in enantioselective alkynylation reactions, and interestingly both central and axial chiralities affect the selectivity of the reaction.

Kamikawa and Uemura elegantly exploited the planar chirality of enantiomerically pure fluoroarene- $\mathrm{Cr}(\mathrm{CO})_{3}$ complexes 92 toward nucleophilic aromatic substitution with substituted indoles (Scheme 43). ${ }^{[59]}$ The reactions proceeded in the presence of $\mathrm{NaH}$ at relatively high temperature but with usually very good diastereoselectivities depending on the substitution at the 2-position of the indole. When 2-substituted indoles $\left(R^{5} \neq\right.$ $\mathrm{H})$ were used, syn-axially chiral $\mathrm{N}$-arylindole- $\mathrm{Cr}(\mathrm{CO})_{3}$ complexes 93 were obtained as major diastereomers (67:33 to >98:2 dr) whereas absence of substitution at $C-2$ resulted in the anti atropisomers 93 , also with excellent diastereoselectivities (96:4 to $>98: 2 d r)$.

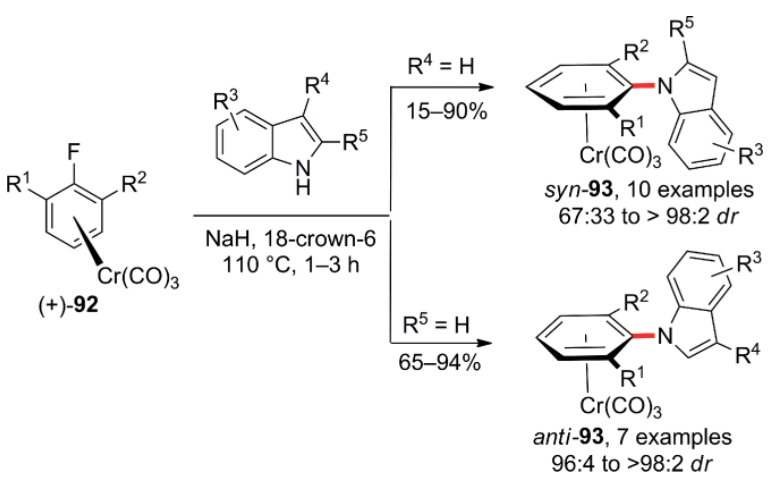

Scheme 43. From planar chirality to axially chiral $\mathrm{N}$-arylindole- $\mathrm{Cr}(\mathrm{CO})_{3} \mathrm{Com}-$ plexes syn- and anti-93.

All of the examples presented until now deal with atropisomers incorporating a five-membered heterocycle. It is quite surprising that only one single example, reported in 1996 by Baker's group, reports the synthesis of atropisomers with an axially chiral C-C-bonded five-membered carbocyclic ring. Thus, the synthesis of enantiomerically pure chiral 1-(3'indenyl)naphthalenes 94 was accomplished thanks to a central-to-axial chirality conversion process ${ }^{[60]}$ involving double bond migration (Scheme 44a). ${ }^{[61 a]}$ The preparation of the ligands 93a and 93b starts with 2-nitro-1-naphthol, which is first converted into the corresponding tosylate. Then, nucleophilic aromatic substitution with 2-methylindenyllithium anion leads to the centrally chiral rotamer 92 in $40 \%$ yield. This undergoes central-to-axial chirality conversion through double bond isomerization upon warming to room temperature to furnish axially chiral 94 in $40 \%$ yield. The nitro function of 94 can be easily converted into 
the corresponding amine by hydrogenation in the presence of platinum on carbon. Also, the amine 93a can be converted into the corresponding axially chiral naphthol $\mathbf{9 3} \mathbf{b}$ by diazotization. Resolution of the ligands is achieved by semipreparative chiral HPLC. Using a related strategy with a chiral sulfoxide auxiliary, the same team also showed the possibility of accessing enantiomerically pure axially chiral ligand 93c, bearing a hydroxymethyl moiety on the naphthyl ring. ${ }^{[61 b]}$ Treatment of $93 \mathrm{c}$ with one equivalent of $\mathrm{Zr}\left(\mathrm{NEt}_{2}\right)_{4}$ enantiospecifically provides the planar chiral zirconium complex 95 in quantitative yield, thanks to a complete axial-to-planar chirality conversion step (Scheme 44b). ${ }^{[61 c]}$

a)<smiles>O=[N+]([O-])c1ccc2ccccc2c1O</smiles>

2)
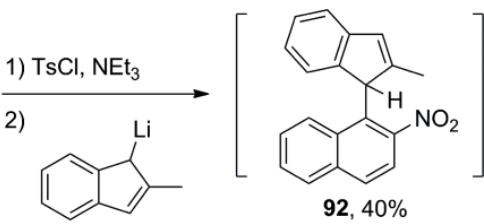

92, $40 \%$
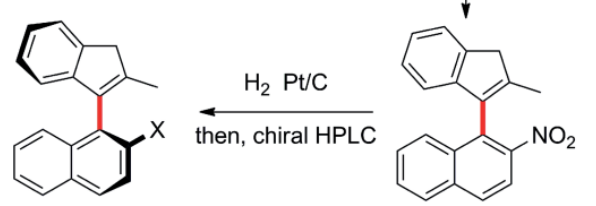
93a, $\mathrm{X}=\mathrm{NH}_{2}, 90 \%$
93b, $\mathrm{X}=\mathrm{OH}, 45 \%$$\longrightarrow$ diazotation

94, $40 \%$ 93b, $X=O H, 45 \%$

$94,40 \%$ b) $93 \mathrm{c}, \mathrm{X}=\mathrm{CH}_{2} \mathrm{OH}$ $>99 \%$ ee

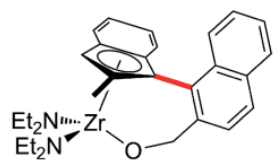

95, $>99 \%$ ee
Scheme 44. Synthesis of atropisomers with an axially chiral C-C-bonded fivemembered carbocyclic ring.

\section{Conclusion and Perspectives}

The synthesis and isolation of stable atropisomers with one axially bonded five-membered cycle is far less developed than that of the more classical six-membered biarylic axially chiral compounds, which are also more widely represented in nature. The main reason for this is increased distances between the crucial ortho-substituents next to the axis, resulting in lower barriers to rotation and higher conformational mobility. Nevertheless, synthetic chemists took up this challenge quite a long time ago, with the first synthesis of a $\mathrm{C}-\mathrm{N}$-bonded arylpyrrole being described in 1931, opening important new synthetic opportunities. The less popular axially chiral $\mathrm{C}-\mathrm{C}$-bonded family was introduced at the end of the 1990s with only few examples and still constitutes a real synthetic challenge for modern organic chemistry. For more than 70 years the isolation of stable enantiomerically pure atropisomers has relied mainly on resolution of racemates or more recently on chromatographic separation on chiral phases, allowing access to new classes of ligands for various metal catalysts and organocatalysts, sometimes also featuring interesting biological or physical properties. A significant synthetic breakthrough appeared with the desymmetrization of privileged structures such as $\mathrm{N}$-arylmaleimides, -succinimides, and other related heterocycles, which has largely been developed in its diastereoselective version and to a lesser extent in some enantioselective transformations. This last point became a tantalizing challenge and has attracted increased interest in the last two years. Notably, thanks to the huge progress in organocatalytic activation methods, various complementary enantioselective approaches have been designed, allowing access to several new families of atropisomers each featuring an axially chiral $\mathrm{C}-\mathrm{N}$ - or $\mathrm{C}-\mathrm{C}$ - bonded five-membered heterocyclic ring of the succinimide, naphthyimide, urazole, indole, pyrrole, thiophene, or furan series. Surprisingly, only one example, reported back in 1996, describes the synthesis of atropisomers with an axially chiral $C(s p 2)-C(s p 2)$ bonded fivemembered carbocyclic ring, whereas an enantioselective synthesis of carbocyclic five-membered atropisomers featuring a stereogenic $C(s p 3)-C(s p 2)$ chemical bond was disclosed very recently.

With this historical overview, we hope that readers will be convinced that the design of ingenious methodologies is still possible and should open the way to other strategies providing new answers to this important synthetic challenge. Moreover, this should produce hitherto unknown chiral molecular species with potential applications for a wide cross-section of chemistry including chiral ligands, organocatalysts, materials, and new biologically relevant compounds.

\section{Acknowledgments}

Financial support from the Agence Nationale pour la Recherche (ANR-13-BS07-0005), the Centre National de la Recherche Scientifique (CNRS), and Aix-Marseille Université is gratefully acknowledged. We warmly thank our colleague Professor Christian Roussel for fruitful discussions and sharing with us his sharp literature knowledge on atropisomerism.

Keywords: Atropisomerism . Five-membered ring atropisomers · Ligand design - Natural products Organocatalysis · Rotational barriers

[1] a) M. C. Kozlowski, B. J. Morgan, E. C. Linton, Chem. Soc. Rev. 2009, 38, 3193-3207; b) G. Bringmann, T. Gulder, T. A. M. Gulder, M. Breuning Chem. Rev. 2011, 111, 563-639; c) A. Zask, J. Murphy, G. A. Ellestad, Chirality 2013, 25, 265-274; d) J. E. Smyth, N. M. Butler, P. A. Keller, Nat. Prod. Rep. 2015, 32, 1562-1583.

[2] For ligands in organometallic catalysis, see: a) R. Noyori, H. Takaya, Acc. Chem. Res. 1990, 23, 345-350; b) M. McCarthy, P. J. Guiry, Tetrahedron 2001, 57, 3809-3844; c) W. Tang, X. Zhang, Chem. Rev. 2003, 103, 30293070; d) H. Shimizu, I. Nagasaki, T. Saito, Tetrahedron 2005, 61, 54055432; e) D. Parmar, E. Sugiono, S. Raja, M. Rueping, Chem. Rev. 2014, 114 , 9047-9153. For organocatalysts, see: f) S. Brandes, B. Niess, M. Bella, A. Prieto, J. Overgaard, K. A. Jørgensen, Chem. Eur. J. 2006, 12, 6039-6052; g) T. Kano, Y. Yamaguchi, K. Maruoka, Chem. Eur. J. 2009, 15, 6678-6687; h) S. Schenker, A. Zamfir, M. Freund, S. B. Tsogoeva, Eur. J. Org. Chem. 2011, 2209-2222.

[3] a) J. Clayden, W. J. Moran, P. J. Edwards, S. R. LaPlante, Angew. Chem. Int. Ed. 2009, 48, 6398-6401; Angew. Chem. 2009, 121, 6516; b) S. R. LaPlante, 
L. D. Fader, K. R. Fandrick, D. R. Fandrick, O. Hucke, R. Kemper, S. P. F. Miller, P. J. Edwards, J. Med. Chem. 2011, 54, 7005-7022.

[4] S. J. Wezenberg, F. Ferroni, S. Pieraccini, W. B. Schweizer, A. Ferrarini, G. P. Spada, F. Diederich, RSC Adv. 2013, 3, 22845-22848.

[5] a) For a review on atropisomerism in heteroaromatic compounds, see: I. Alkorta, J. Elguero, C. Roussel, N. Vanthuyne, P. Piras, Adv. Heterocycl. Chem. 2012, 105, 1-188; b) A. Djafri, C. Roussel, J. Sandström, J. Chem. Soc. Perkin Trans. 2 1985, 273-277; c) J. C. Lomas, J.-C. Lacroix, J. Vaissermann, J. Chem. Soc. Perkin Trans. 2 1999, 2001-2010.

[6] For carbocylic series, see: a) M. Oki, Top. Stereochem. 1983, 14, 1-81; b) G. Bringmann, A. J. Price Mortimer, P. A. Keller, M. J. Gresser, J. Garner, M. Breuning, Angew. Chem. Int. Ed. 2005, 44, 5384-5427; Angew. Chem 2005, 117, 5518. c) J. Wencel-Delord, A. Panossian, F. R. Leroux, F. Colobert, Chem. Soc. Rev. 2015, 44, 3418-3430; d) S. Shirakawa, S. Liu, S. Kaneko, Chem. Asian J. 2016, 11, 330-341; e) Special issue, F. Colobert (Ed.), Methods for Controlling Axial Chirality, Tetrahedron 2016, 72, 5157; f) For a highlight, see: O. Quinonero, C. Bressy, X. Bugaut, Angew. Chem. Int. Ed. 2014, 53, 10861-10863; Angew. Chem. 2014, 126, 11039. For heterocyclic series, see: g) T. J. Donohoe, C. R. Jones, A. F. Kornahrens, L. C. A Barbosa, L. J. Walport, M. R. Tatton, M. OÏHagan, A. H. Rathi, D. B. Baker, J. Org. Chem. 2013, 78, 12338-12350; h) T. Shibuya, Y. Shibata, K. Noguchi, K. Tanaka, Angew. Chem. Int. Ed. 2011, 50, 3963-3967; Angew. Chem. 2011, 123, 4049; i) E. Kumarasamy, R. Raghunathan, M. P. Sibi, J. Sivaguru, Chem. Rev. 2015, 115, 11239-11300.

[7] M. Oki, Top. Stereochem. 1983, 14, 1-81.

[8] For pioneering observations and dynamic NMR experimental determination of barriers to rotation in the $\mathrm{N}$-arylhydantoin, -oxazoline, -imidazoline, -thiazoline, and succinimide series, see: a) $\mathrm{H}$. Kalinowski, $\mathrm{H}$. Kessler, Top. Stereochem. 1972, 7, 295-383; b) L. D. Colebrook, H. G. Giles, A. Granata, S. Icli, J. R. Fehlner, Can. J. Chem. 1973, 51, 3635-3639; c) P. H. Bird, L. D. Colebrook, A. R. Fraser, H. G. Giles, J. Chem. Soc., Chem. Commun. 1974, 225-226; d) S. M. Verma, N. B. Singh, Aust. J. Chem. 1976, 29, 295-300.

[9] R. S. Norton, R. J. Wells, J. Am. Chem. Soc. 1982, 104, 3628-3635.

[10] C. Ito, Y. Thoyama, M. Omura, I. Kjiura, H. Furukawa, Chem. Pharm. Bull. 1993, 41, 2096-2100

[11] G. Bringmann, S. Tasler, H. Endress, J. Kraus, K. Messer, M. Wohlfarth, W. Lobin, J. Am. Chem. Soc. 2001, 123, 2703-2711.

[12] a) C. C. Hughes, A. Pietro-Davo, P. R. Jensen, W. Fenical, Org. Lett. 2008 10, 629-631; b) P. Schneider, G. Schneider, Chem. Commun, 2017, 53, 2272-2274; c) C. Cheng, L. Pan, Y. Chen, H. Song, Y. Qin, R. Li, J. Comb. Chem. 2010, 12, 541-547; d) A. A. Kanakis, V. Sarli, Org. Lett. 2010, 12 4872-4875.

[13] a) For another naturally occurring but achiral $C-N$-bonded arylpyrrole alkaloid - lamellarin-R - see: S. Urban, L. Hobbs, J. N. A. Hooper, R. J. Capon, Aust J. Chem 1995, 48, 1491-1494; b) For the unusual non-natural $\mathrm{C}-\mathrm{N}$-aryl pyrrole (-)-rhazinilam, obtained by oxidative aromatization during isolation of the corresponding non-biarylic 5,21 dihydrorhazinilam natural product, see: K. T. De Silva, A. H. Ratcliffe, G. F. Smith, G. N. Smith, Tetrahedron Lett. 1972, 13, 913.

[14] For an early compilation, see: I. Takahashi, Y. Suzuki, O. Kitagawa, Org Prep. Proced. Int. 2014, 46, 1-23.

[15] a) L. H. Bock, R. Adams, J. Am. Chem. Soc. 1931, 53, 374-376; b) L. H. Bock, R. Adams, J. Am. Chem. Soc. 1931, 53, 3519-3522.

[16] a) W. I. Patterson, R. Adams, J. Am. Chem. Soc. 1933, 55, 1069-1072; b) For an unusual chiral di- $N$-naphthyl-fused indolocarbazole with holetransporting performance in organic LED devices, see: N.-X. Hu, S. Xie, Z Popovic, B. Ong, A.-M. Hor, J. Am. Chem. Soc. 1999, 121, 5097-5098.

[17] R. Adams, R. M. Joyce Jr., J. Am. Chem. Soc. 1938, 60, 1491-1492.

[18] a) C. Roussel, M. Adjimi, A. Chemlal, A. Djafri, J. Org. Chem. 1988, 53, 5076-5080, and references cited therein; b) R. Gallo, C. Roussel, Adv. Heterocyl. Chem. 1988, 43, 173-299; c) A. Hîrtopeanu, C. Suteu, C. Uncuta, G. Mihai, C. Roussel, Eur. J. Org. Chem. 2000, 1081-1090; d) C. Roussel, B. Bonnet, A. Piederriere, C. Suteu, Chirality 2001, 13, 56-61; e) W. H. Pirkle, M. E. Koscho, Z. Wu, J. Chromatogr. A 1996, 726, 91-97; f) W. H. Pirkle, L. J. Brice, G. T. Terfloth, J. Chromatogr. A 1996, 753, 109-119; g) see also ref. 11b; h) I. Doğan, N. Pustet, A. Mannschreck, J. Chem. Soc. Perkin Trans. 2 1993, 1557-1560; i) E. M. Yilmaz, I. Doğan, Tetrahedron: Asymmetry 2008, 19, 2184-2191 and reference cited therein; j) C. Roussel, M. Roman, F. Andreoli, A. Del Rio, R. Faure, N. Vanthuyne, Chirality
2006, 18, 762-771; k) Happaz-Gillot, G. Canard, F. Andreoli, N. Vanthuyne, M. Giorgi, J.-V. Naubron, V. Monnier, R. Rosas, C. Roussel, T. S. Balaban, Eur. J. Org. Chem. 2012, 6526-6536.

[19] a) S. Erol, I. Doğan, J. Org. Chem. 2007, 72, 2494-2500; b) S. Erol, I. Doğan, Chirality 2012, 24, 493-498; c) C. Roussel, N. Vanthuyne, M. Bouchekara, A. Djafri, J. Elguero, I. Alkorta, J. Org. Chem. 2008, 73, 403-411; d) B. E. Dial, P. J. Pellechia, M. D. Smith, K. D. Shimizu, J. Am. Chem. Soc. 2012 134, 3675-3678; e) R. D. Rasberry, K. D. Shimizu, Org. Biomol. Chem. 2009, 7, 3899-3905; f) B. E. Dial, R. D. Rasberry, B. N. Bullock, M. D. Smith, P. Pellechia, S. Proheta, K. D. Shimizu, Org. Lett. 2011, 13, 244-247.

[20] a) J. Vorkapić-Furač, M. Mintas, F. Kastner, A. Mannschreck, J. Heterocycl. Chem. 1992, 29, 327-333; b) N. Raos, M. Mintas, Croat. Chem. Acta 1992 65, 893-899.

[21] a) D. J. Bennett, A. J. Blake, P. A. Cooke, C. R. A. Godfrey, P. L. Pickering N. S. Simpkins, M. D. Walker, C. Wilson, Tetrahedron 2004, 60, 4491-4511 b) R. J. Brown, G. Annis, A. Casalnuovo, D. Chan, R. Shapiro, W. J. Marshall, Tetrahedron 2004, 60, 4361-4375. c) T. Sugane, N. Hamada, T. Tobe, W. Hamaguchi, I. Shimada, K. Maeno, J. Miyata, T. Suzuki, T. Kimizuka, S. Sakamoto, S.-I. Tsukamoto, Tetrahedron: Asymmetry 2012, 23, 1528-1533.

[22] A. Ciogli, S. V. Kumar, M. Mancinelli, A. Mazzanti, S. Perumal, C. Severi, C. Villani, Org. Biomol. Chem. 2016, 14, 11137-11147.

[23] F. Sannicolò, S. Arnaboldi, T. Benincori, V. Bonometti, R. Cirilli, L. Dunsch, W. Kutner, G. Longhi, P. R. Mussini, M. Panigati, M. Pierini, S. Rizzo, Angew. Chem. Int. Ed. 2014, 53, 2623-2627; Angew. Chem. 2014, 126, 2661

[24] a) T. Bruhn, G. Pescitelli, S. Jurinovich, A. Schaumlöffel, F. Witterauf, J. Ahrens, M. Bröring, G. Bringmann, Angew. Chem. Int. Ed. 2014, 53, 1459214595; Angew. Chem. 2014, 126, 14821; b) P. J. Chmielewski, M. Siczek M. Stępień, Chem. Eur. J. 2015, 21, 2547-2559.

[25] E. Van Den Berge, J. Pospišil, T. Trieu-Van, L. Collard, R. Robiette, Eur. J. Org. Chem. 2011, 6649-6655.

[26] a) S. F. Rak, T. H. Jozefiak, L. L. Miller, J. Org. Chem. 1990, 55, 4794-4801; b) D. P. Curran, H. Qi, S. J. Geib, N. C. DeMello, J. Am. Chem. Soc. 1994 116, 3131-3132; c) D. P. Curran, H. Qi, S. J. Geib, N. C. DeMello, Tetrahedron 1999, 55, 5681-5704; d) K. Kishikawa, I. Tsuru, S. Kohomoto, M Yamamoto, K. Yamada, Chem. Lett. 1994, 23, 1605-1606; e) K. Kishikawa, K. Yoshizaki, S. Kohomoto, M. Yamamoto, K. Yamaguchi, K. Yamada, J Chem. Soc. Perkin Trans. 1 1997, 1233-1239.

27] a) O. Kitagawa, H. Izawa, K. Sato, A. Dobashi, T. Taguchi, J. Org. Chem. 1998, 63, 2634-2640; b) M. Fujita, O. Kitagawa, Y. Yamada, H. Izawa, H. Hasegawa, T. Taguchi, J. Org. Chem. 2000, 65, 1108-1114.

[28] M. Sakamoto, M. Shigekura, A. Saito, T. Ohtake, T. Mino, T. Fujita, Chem Commun. 2003, 2218-2219.

[29] a) A. M. Said, G. P. Savage, J. Org. Chem. 2011, 76, 6946-6950; b) N. J. Beattie, C. L. Francis, A. J. Liepa, G. P. Savage, Aust. J. Chem. 2010, 63, 445-451.

[30] S. Erol, I. Doğan, Tetrahedron 2013, 69, 1337-1344.

[31] A. Nakazaki, A. Mori, S. Kobayashi, T. Nishikawa, Tetrahedron Lett. 2012 $53,7131-7134$.

[32] J. L. Jesuraj, J. Sivaguru, Chem. Commun. 2010, 46, 4791-4793.

[33] C. F. Degenhardt III, J. M. Lavin, M. D. Smith, K. D. Shimizu, Org. Lett. 2005, 7, 4079-4081.

[34] S. Sarigul, I. Doğan, J. Org. Chem. 2016, 81, 5895-5902.

[35] J. Rae, J. Frey, S. Jerhaoui, S. Choppin, J. Wencel-Delord, F. Colobert, ACS Catal. 2018, https://doi.org/10.1021/acscatal.7b04343</o.

[36] D. Bonne, J. Rodriguez, Chem. Commun. 2017, 53, 12385-12393.

[37] V. S. Raut, M. Jean, N. Vanthuyne, C. Roussel, T. Constantieux, C. Bressy, X. Bugaut, D. Bonne, J. Rodriguez, J. Am. Chem. Soc. 2017, 139, 21402143.

38] D. Wang, X. Tong, Org. Lett. 2017, 19, 6392-6385.

[39] L.-W. Qi, J.-H. Mao, J. Zhang, B. Tan, Nat. Chem. 2018, 10, 58-64.

[40] N. Di lorio, G. Filippini, A. Mazzanti, P. Righi, G. Bencivenni, Org. Lett. 2017, 19, 6692-6695.

[41] a) N. Debono, Y. Canac, C. Duhayon, R. Chauvin, Eur. J. Inorg. Chem. 2008 2991-2999; b) I. Abdellah, N. Debono, Y. Canac, L. Vendier, R. Chauvin, Chem. Asian J. 2010, 5, 1225-1231.

[42] a) T. Mino, Y. Tanaka, Y. Hattori, T. Yabusaki, H. Saotome, M. Sakamoto, T. Fujita, J. Org. Chem. 2006, 71, 7346-7353; b) T. Mino, K. Wakui, S. Oishi, Y. Hattori, M. Sakamoto, T. Fujita, Tetrahedron: Asymmetry 2008, 19, 2711 2716; c) T. Mino, S. Komatsu, K. Wakui, H. Yamada, H. Saotome, M. Sakamoto, T. Fujita, Tetrahedron: Asymmetry 2010, 21, 711-718; d) T. Mino, M. 
Ishikawa, K. Nishikawa, K. Wakui, M. Sakamoto, Tetrahedron: Asymmetry 2013, 24, 499-504.

[43] a) F. Faigl, B. Mátravölgyi, A. Szöllősy, M. Czugler, G. Tárkányi, K. Vékey, M. Kubinyi, Chirality 2012, 24, 532-542; b) F. Faigl, B. Mátravölgyi, T. Holczbauer, M. Czugler, J. Madarász, Tetrahedron: Asymmetry 2011, 22, 1879-1884; C) F. Faigl, B. Vas-Feldhoffer, V. Kudar, M. Czugler, K. Pál, M. Kubinyi, Chirality 2009, 21, 905-910; d) K. Fogassy, V. Harmat, Z. Böcskei, G. Tárkányi, L. Tőke, F. Faigl, Tetrahedron: Asymmetry 2000, 11, 47714780; e) F. Faigl, Z. Erdélyi, S. Deák, M. Nyerges, B. Mátravölgyi, Tetrahedron Lett. 2014, 55, 6891-6894.

[44] a) F. Faigl, A. Thurner, J. Kovári, G. Tárkányi, L. Tőke, A. Mordini, Tetrahedron: Asymmetry 2002, 13, 59-68; b) F. Faigl, G. Tárkányi, K. Fogassy, D. Tepfenhardt, A. Thurner, Tetrahedron 2008, 64, 1371-1377.

[45] a) Shimizu, H. O. Freyer, R. D. Adams, Tetrahedron Lett. 2000, 41, 5431 5434; b) Y. Chen, M. D. Smith, K. D. Shimizu, Tetrahedron Lett. 2001 427185-7187; c) see ref. ${ }^{[33]}$.

[46] a) M. N. Hopkinson, C. Richter, M. Schedler, F. Glorius, Nature 2014, 510, 485-496; b) S. Bellemin-Laponnaz, S. Dagorne, Chem. Rev. 2014, 114, 8747-8774; c) D. M. Flanigan, F. Romanov-Michailidis, N. A. White, T. Rovis, Chem. Rev. 2015, 115, 9307-9387; d) E. Peris, Chem. Rev. 2017 https://doi.org/10.1021/acs.chemrev.6b00695; e) For one isolated example of a related axially chiral cyclic amidinium derivative with a barrier to rotation of $101 \mathrm{~kJ} \mathrm{~mol}^{-1}$, see: U. Berg, R. Isaksson, J. Sandström, U. Sjöstrand, A. Eiglsperger, A. Mannschreck, Tetrahedron Lett. 1982, 23, 4237-4240.

[47] a) T. J. Seiders, D. W. Ward, R. H. Grubbs, Org. Lett. 2001, 3, 3225-3228; b) J. J. Van Veldhuizen, S. B. Garber, J. S. Kingsbury, A. H. Hoveyda, J. Am Chem. Soc. 2002, 124, 4954-4955; c) For other more recent generations, see: J. J. Van Veldhuizen, D. G. Gillingham, S. B. Garber, O. Kataoka, A. H. Hoveyda, J. Am. Chem. Soc. 2003, 125, 12502-12508; d) T. W. Funk, J. M. Berlin, R. H. Grubbs, J. Am. Chem. Soc. 2006, 128, 1840-1846; e) H. W. Jeannette, M. Garcia, F. Haeffner, S. Radomkit, A. R. Zhugralin, A. H. Hov eyda, J. Am. Chem. Soc. 2015, 137, 10585-10602; f) Y. Shi, A. H. Hoveyda, Angew. Chem. Int. Ed. 2016, 55, 3455-3458; Angew. Chem. 2016, 128 3516.

[48] J. Pesch, K. Harms, T. Bach, Eur. J. Org. Chem. 2004, 2025-2035.

[49] a) E. Bappert, G. Helmchen, Synlett 2004, 1789-1793; b) For examples of related chiral concave $\mathrm{N}$-naphthylimidazolium salts and $\mathrm{NHCs}$, see: $\mathrm{O}$ Winkelmann, D. Linder, J. Lacour, C. Näther, U. Lüning, Eur. J. Org. Chem. 2007, 3687-3697.

[50] a) X. Luan, R. Mariz, M. Gatti, C. Costabile, A. Poater, L. Cavallo, A. Linden, R. Dorta, J. Am. Chem. Soc. 2008, 130, 6848-6858; b) L. Vieille-Petit, X Luan, R. Mariz, S. Blumentritt, A. Linden, R. Dorta, Eur. J. Inorg. Chem. 2009, 1861-1870.

[51] a) I. Abdellah, M. Boggio-Pasqua, Y. Canac, C. Lepetit, C. Duhayon, R. Chauvin, Chem. Eur. J. 2011, 17, 5110-5115; b) I. Abdellah, N. Debono, Y. Canac, C. Duhayon, R. Chauvin, Dalton Trans. 2009, 7196-7202; C) F. Wang, S. li, M. Qu, M.-X. Zhao, L.-J. Liu, M. Shi, Chem. Commun. 2011, 47, 12813-12815.
[52] For reviews on biheteroaromatic atropisomeric diphosphines and their transition-metal complexes, see: a) T. Benincori, S. Rizzo, F. Sannicolò, J. Heterocycl. Chem. 2002, 39, 471-485; b) T. T.-L. Au-Yeung, A. S. C. Chan, Coord. Chem. Rev. 2004, 248, 2151-2164.

[53] T. Benincori, S. Gladiali, S. Rizzo, F. Sannicolò, J. Org. Chem. 2001, 66, 5940-5942.

[54] a) T. Benincori, E. Cesarotti, O. Piccolo, F. Sannicolò, J. Org Chem 2000 65, 2043-2047; b) T. Benincori, E. Brenna, F. Sannicolò, L. Trimarco, P. Antognazza, E. Cesarotti, J. Chem. Soc., Chem. Commun. 1995, 685-686; c) T. Benincori, E. Brenna, F. Sannicolò, L. Trimarco, P. Antognazza, E. Cesarotti, F. Demartin, T. Pilati, J. Org. Chem. 1996, 61, 6244-6251; d) U. Berens, J. M. Brown, J. Long, R. Selke, Tetrahedron: Asymmetry 1996, 7, 285-292; e) T. Benincori, E. Brenna, F. Sannicolò, L. Trimarco, P. Antognazza, E. Cesarotti, F. Demartin, T. Pilati, G. Zotti, J. Organomet. Chem. 1997, 529, 445-453; f) T. Benincori, O. Piccolo, S. Rizzo, F. Sannicolò, J. Org. Chem. 2000, 65, 8340-8347; g) For the unique $\mathrm{N}-\mathrm{N}$-axially bonded atropisomeric benzimidazole 89a, see: P. Antognazza, T. Benincori, S. Mazzoli, F. Sannicolò, T. Pilati, Phosphorus Sulfur Silicon Relat. Elem. 1999, 144-146, 405-408; h) G. Celentano, T. Benincori, S. Radaelli, M. Sada, F. Sannicolò, J. Organomet. Chem. 2002, 643-644, 424-430; i) A. Figge, H. J. Altenbach, D. J. Brauer, P. Tielmann, Tetrahedron: Asymmetry 2002, 13, 137-144.

[55] a) L. F. Tietze, K. Thede, F. Sannicolò, Chem. Commun. 1999, 1811-1812 b) L. F. Tietze, K. Thede, R. Schimpf, F. Sannicolò, Chem. Commun. 2000, 583-584.

[56] N. Andersen, M. Parvez, B. A. Keay, Org. Lett. 2000, 2, 2817-2820.

[57] a) F. S. P. Cardoso, K. A. Abboud, A. Aponick, J. Am. Chem. Soc. 2013, 135 14548-14551; b) M. Pappoppula, F. S. P. Cardoso, B. O. Garett, A. Aponick Angew. Chem. Int. Ed. 2015, 54, 15202-15206; Angew. Chem. 2015, 127 , 15417 ; c) P. H. S. Paioti, K. A. Abboud, A. Aponick, J. Am. Chem. Soc. 2016 138, 2150-2153; d) S. Mishra, J. Liu, A. Aponick, J. Am. Chem. Soc. 2017, $139,3352-3355$.

[58] a) B. V. Rokade, P. J. Guiry, ACS Catal. 2017, 7, 2334-2338; b) P. H. S Paioti, K. A. Abboud, A. Aponick, ACS Catal. 2017, 7, 2133-2138.

[59] a) K. Kamikawa, S. Kinoshita, M. Furusyo, S. Takemoto, H. Matsuzaka, M. Uemura, J. Org. Chem. 2007, 72, 3394-3402; b) S. Kinoshita, K. Kamikawa, Tetrahedron 2016, 72, 5202-5207.

[60] For a recent example of central-to-axial chirality conversion, see: O. Quinonero, M. Jean, N. Vanthuyne, C. Roussel, D. Bonne, T. Constantieux, C. Bressy, X. Bugaut, J. Rodriguez, Angew. Chem. Int. Ed. 2016, 55, 14011405; Angew. Chem. 2016, 128, 1423.

[61] a) R. W. Baker, J. A. Taylor, Tetrahedron Lett. 2000, 41, 4471-4473; b) R. W. Baker, T. W. Hambley, P. Turner, B. J. Wallace, Chem. Commun. 1996 2571-2572; c) R. W. Baker, B. J. Wallace, Chem. Commun. 1999, 14051406. 